\title{
Polycystic ovarian syndrome: Proposal for an evidence -based management plan for an electronic patient record system
}

\author{
Mary Elizabeth DuRant \\ West Virginia University
}

Follow this and additional works at: https://researchrepository.wvu.edu/etd

\footnotetext{
Recommended Citation

DuRant, Mary Elizabeth, "Polycystic ovarian syndrome: Proposal for an evidence -based management plan for an electronic patient record system" (2010). Graduate Theses, Dissertations, and Problem Reports. 3515.

https://researchrepository.wvu.edu/etd/3515

This Dissertation is protected by copyright and/or related rights. It has been brought to you by the The Research Repository @ WVU with permission from the rights-holder(s). You are free to use this Dissertation in any way that is permitted by the copyright and related rights legislation that applies to your use. For other uses you must obtain permission from the rights-holder(s) directly, unless additional rights are indicated by a Creative Commons license in the record and/ or on the work itself. This Dissertation has been accepted for inclusion in WVU Graduate Theses, Dissertations, and Problem Reports collection by an authorized administrator of The Research Repository @ WVU. For more information, please contact researchrepository@mail.wvu.edu.
} 
Polycystic Ovarian Syndrome:

Proposal for an Evidence-based Management Plan

for an Electronic Patient Record System

Mary Elizabeth DuRant, MSN, WHNP-BC, CNM

Doctoral Research Project submitted to the

School of Nursing

at West Virginia University

in partial fulfillment of the requirements

for the degree of

Doctor of Nursing Practice

Nan S. Leslie, Ph.D., RNC, WHNP-BC, Chair

Susan H. McCrone, Ph.D., PMHCNS-BC, RN

Laura Davisson, MD, MPH

School of Nursing

Morgantown, West Virginia

2010

Keywords: polycystic ovarian syndrome, PCOS, electronic charting, chronic illness 


\begin{abstract}
Polycystic Ovarian Syndrome: Proposal for an Evidence-based Management Plan for an Electronic Patient Record System

Mary Elizabeth DuRant
\end{abstract}

The goal of this change project was to improve the diagnosis and management of women with polycystic ovarian syndrome (PCOS) through the use of an electronic patient record system. PCOS is one of the top ten missed or delayed diagnoses as well as an inconsistently or mismanaged women's health issue in primary care.

The chronic care model, known pathophysiology, and evidence-based research composed the framework used in developing the diagnosis and management plan for an electronic record system in a free health care clinic.

The project was evaluated based on the following four objectives: 1 . To provide an educational session at a free clinic to increase providers' knowledge about diagnosing PCOS; 2. To assess health care providers' knowledge about PCOS and its management before and after an educational session; 3 . To develop a management plan and imbed the plan in an electronic patient record system at the free clinic to improve efficiency and quality of care for PCOS management; 4 . To evaluate the effectiveness of an electronic management plan in increasing the frequency of diagnosis and appropriateness of treatment of PCOS at the free clinic. Objective one was evaluated by testing providers' knowledge before and after the educational session. Preand post educational session chart review was used to evaluate objectives two through four. Thirty- four total charts met the inclusion criteria for evaluation for this project.

Analysis of the data revealed a significant improvement in knowledge level of providers after the educational session. However, no statistically significant difference between pre and post educational session was found in diagnosing and managing the metabolic status of the PCOS population at the clinic.

This project is an initial step in utilizing technology to improve diagnosis and management of a frequently misdiagnosed or under diagnosed and mismanaged common chronic syndrome on women. 


\section{Acknowledgements}

I wish to thank the members of my capstone committee for their contributions and support as I developed, implemented, and evaluated this capstone project. I thank Dr. Leslie, who served as the chair for the committee, for her unfailing support and constantly challenging me to rise to a higher level in thinking and performance in both academia and in the clinical setting. Many of the achievements I have obtained would not have happened without her belief in my abilities and gently nudging to keep me moving forward. I thank Dr. Susan McCrone for her patient support. She taught me to look critically at the evidence, and to apply it in both my academic work and practice. I thank Dr. Laura Davisson for serving as the content expert on the committee. The committee was instrumental in assisting me to develop a scholarly project. 
Table of Contents

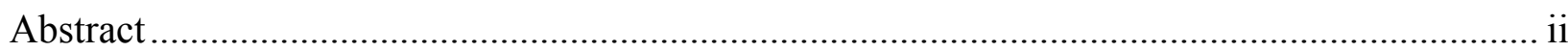

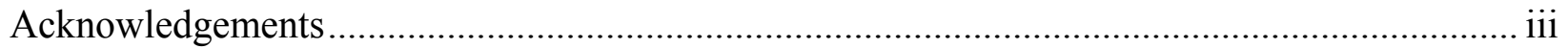

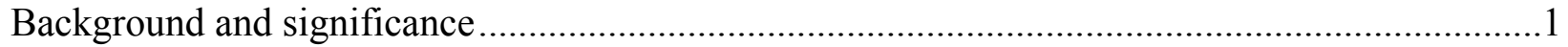

Scope of the problem related to PCOS ..................................................................2

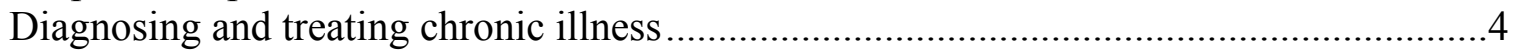

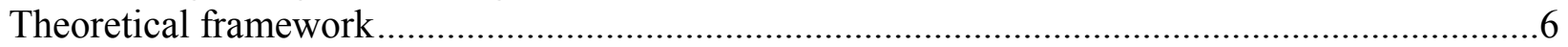

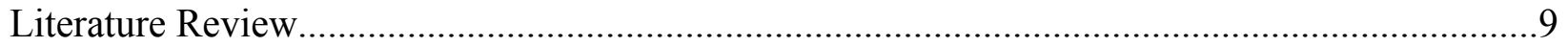

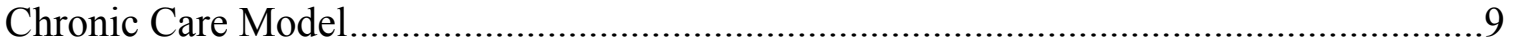

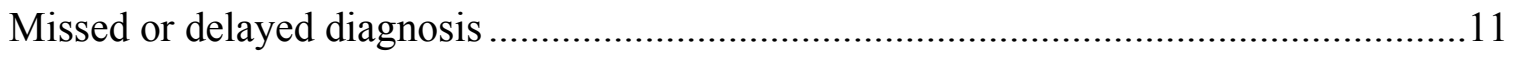

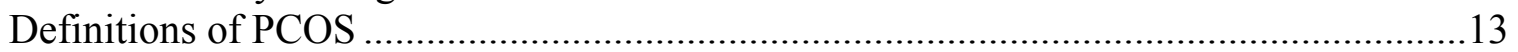

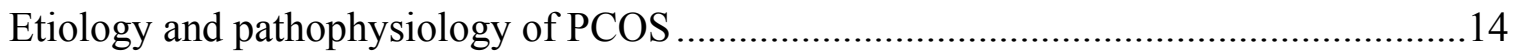

Clinical consequences of PCOS pathophysiology ….............................................. 17

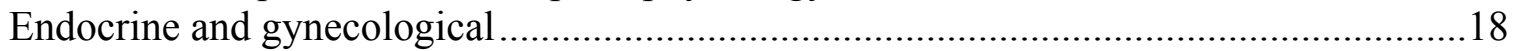

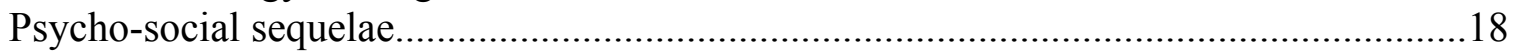

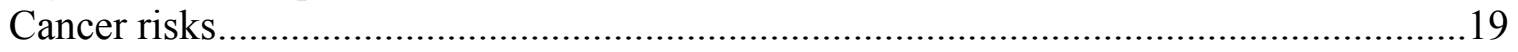

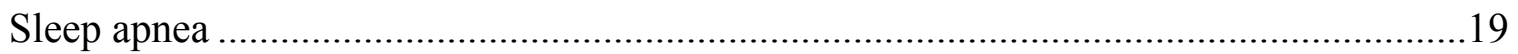

Infertility, high risk pregnancy, and potential delayed lactogenesis..............................20

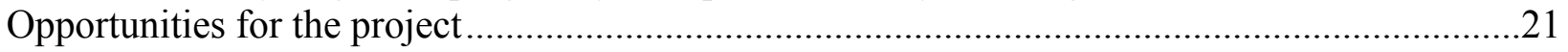

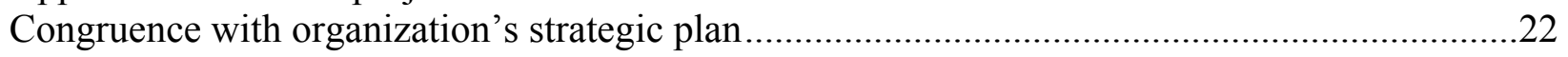

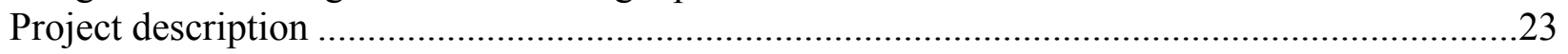

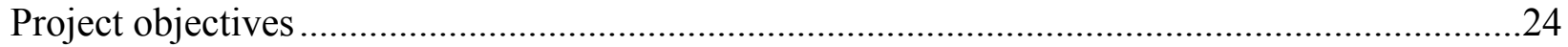

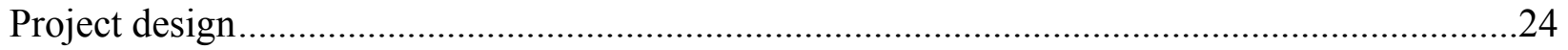

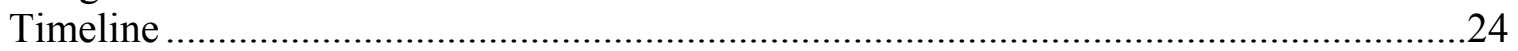

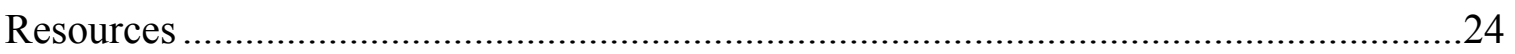

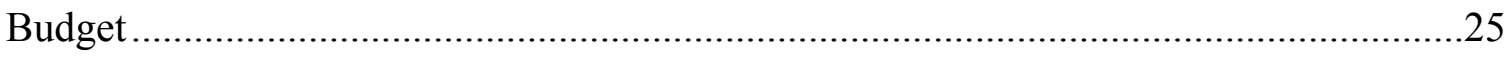

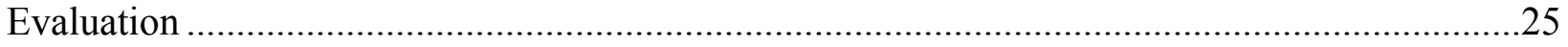

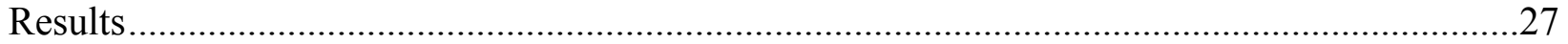

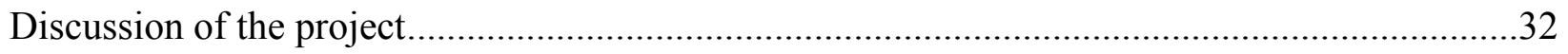

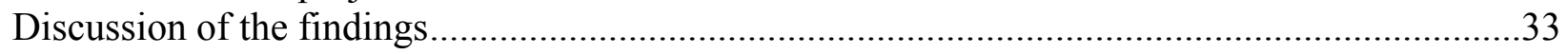

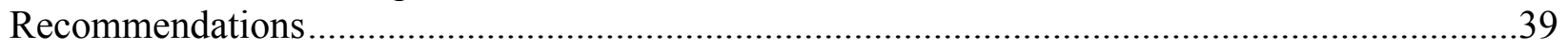

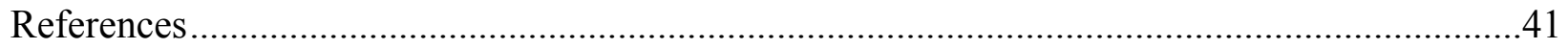

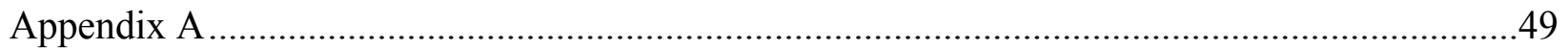

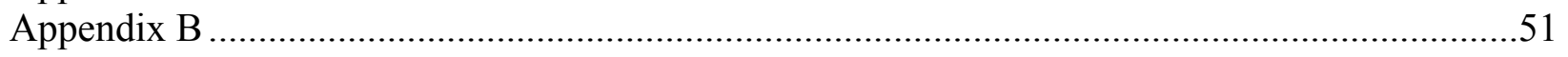

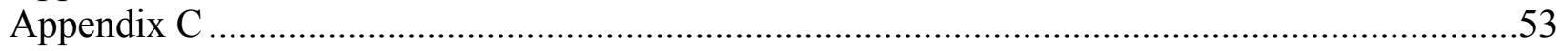

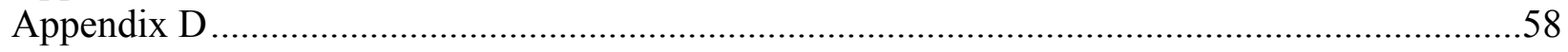

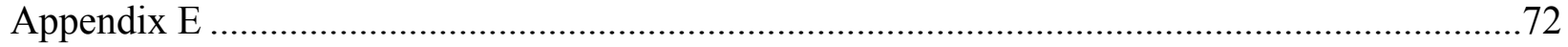

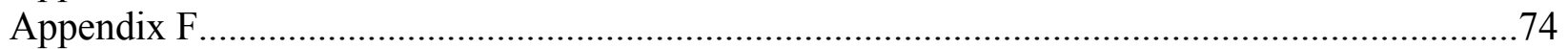

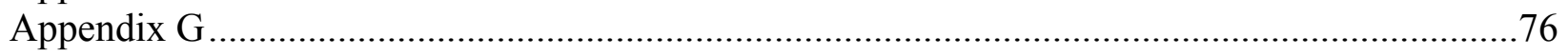

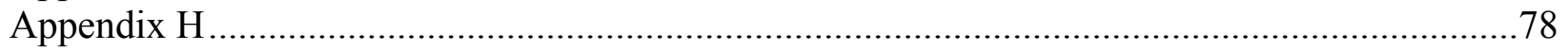

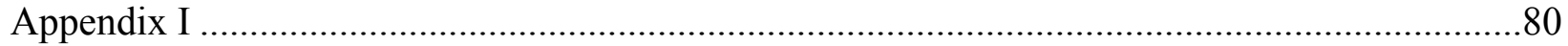

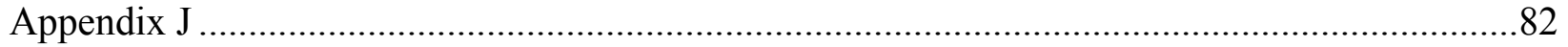

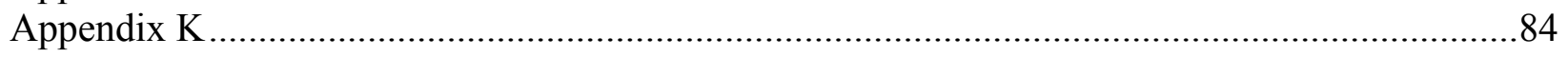

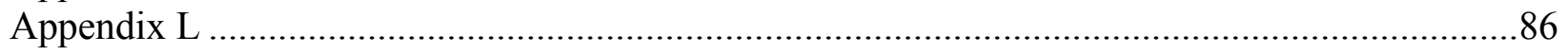


PCOS Project 1

Polycystic Ovarian Syndrome: Proposal for an Evidence-based Management Plan for an Electronic Patient Record System

Background and Significance

Polycystic ovarian syndrome (PCOS), the most common endocrine disease of women of reproductive age, affects $5 \%$ to $10 \%$ of women, causing lifelong ramifications which affect women's health (Dunaif, Givens, Haseltine, \& Merriam, 1992; Hart, Hickey, \& Franks, 2004). Despite PCOS being a common health problem in women, it is frequently under diagnosed and inconsistently managed (Tomlinson, \& Pinkney, 2007). It is one of the top ten missed diagnoses in primary care. Multiple reasons contribute to this syndrome being difficult to diagnose during its early manifestation. The leading factors that contribute to missing a diagnosis by a provider include: failures in judgment (79\%); vigilance or memory (59\%); knowledge deficit (48\%); and patient-related factors (46\%) such as atypical clinical presentation (15\%), and complicated medical history (10\%) (Gandhi, et al., 2006).

In the case of PCOS, many reasons contribute an initial missed diagnosis by the health care provider. PCOS is a group of symptoms, signs, and biochemical features that occur in various combinations and with varying degrees of severity (Elghblawi, 2007). The predominant symptoms of PCOS, such as hirsutism and irregular or absent menstrual cycles, can be present due to other causes. The heterogeneous nature of this endocrine disorder causes women to present to various health care settings for help. With resolution of the problem, the patient may not return for further evaluation to determine the underlying cause of the initial problem. The inconsistencies in the investigation and management of PCOS compound this problem of failure to diagnose. 
PCOS is a chronic endocrine disorder that has a major impact on the reproductive, metabolic, and cardiovascular health of affected women. Women with PCOS are at risk for developing type 2 diabetes mellitus, hyperlipidemia, endometrial cancer, and infertility problems (Ehrmann, 2005; Guzick, 2004; Sherif, 2006; Taylor, 1998). Providers in a free clinic in a West Virginia (WV) community which serves uninsured lower income people treat a population of women from 18 to 65 years of age. This clinic is the only access to primary health care these patients. The clinic is staffed by a variety of physicians and advanced practice nurse practitioners who volunteer their time or receive a small compensation for their services. Thus, providers from various specialties staff this clinic. It is therefore essential to educate primary care providers from differing health care specialties, nurses and other health care professionals about the criteria used to establish a diagnosis of PCOS in female patients. These practitioners must learn to initiate a management plan to prevent or minimize the complications and consequences of the disease. Scope of the Problem Related to PCOS; Necessary Knowledge Base for Health Care Providers

PCOS is a complex syndrome that does not present with a consistent set of symptoms. The sum of the whole syndrome causes greater morbidity than the complications from each individual symptom. The genetic component and the presentation of menstrual irregularities in adolescence may cause both the adolescent and the health care provider to assume these symptoms are normal because they have occurred in other women in the family and irregular menses is common in early puberty (Meisler, 2002).

Ideally, the diagnosis of PCOS should be suspected in childhood, and suspected if other women in the family have PCOS or have obesity with type 2 diabetes mellitus. Irregular menstrual cycles may be the first presenting symptom to suggest the existence of PCOS. Care in pediatrics, family medicine, or gynecology is often sought initially for help in regulating 
menstrual cycles or in early adulthood to treat infertility. Oligo-ovulation manifests as menstrual irregularity and occurs in $70 \%$ of women with PCOS. Women with PCOS often report irregular menstrual patterns, and experience varying degrees of ovulatory dysfunction. Often the menstrual pattern (i.e., three to five days of menstrual flow every 28 to 35 days) occurs for the first one to two years after menarche (which occurs at the normal age), but menses then become less frequent, occurring every 45 to 365 days (Richardson, 2003). After the onset of puberty, $75 \%$ of women with secondary amenorrhea meet the diagnostic criteria for PCOS (Azziz, et al, 2006; Hill, 2003; King, 2007). This is why the diagnosis tends to be made post-puberty.

Women enter the health care system seeking care for the individual symptoms causing a problem. Because there is a wide range of problems which result from PCOS, young teens and women enter the health care system seeking care from practitioners from many health care disciplines. Women often seek the care of the practitioner who they feel is appropriate to manage the immediate problem. Thus the immediate diagnosis, such as irregular menses, diabetes, or acne may be treated, but the diagnosis of PCOS may be delayed (Birnbaum, 2003).

Hyperandrogenemia is present in $60 \%$ to $80 \%$ of women with PCOS (Azziz, et al, 2006). Elevated androgens cause hirsutism in $60 \%$ of sufferers, acne in $15 \%$ to $25 \%$, and androgenic alopecia in an estimated 5\% of women with PCOS (Azziz, et al.). The diagnosis may be made when women begin seeking help with dermatological or hair removal problems (Salmi, Zisser, \& Jovanovic, 2004).

Qualitative studies report phenotypic characteristics of PCOS affect quality of life and self esteem for these women. In Snyder's study (2006), women with PCOS recognized themselves as different from other women without the disease, as the syndrome manifests with varying symptoms. Higher than average weight gain, lack of regular menstrual cycles, very 
PCOS Project 4

heavy or continuous bleeding with occasional menses, growth of excessive unwanted facial and body hair, and severe mood swings were identified as the characteristics that made PCOS sufferers feel different. Patients with PCOS also expressed that feeling different created a sense of insecurity and isolation (Snyder). Obesity also contributed to a sense of being not normal or not looking like the media portrayal of femininity (Snyder). Women with PCOS identify that being a normal female means looking more female (without hirsutism), having a beautiful complexion, and having regular menstrual cycles (Snyder). They recognized that hirsutism and infertility problems made them feel less feminine as though womanhood had been stolen (Kitzinger \& Wilmot, 2002; Snyder). The physical signs of PCOS can be detrimental to a teenage girl's self-image. Early diagnosis and treatment in adolescents are essential in ensuring health in adulthood and restoring self-esteem (Salmi, et al., 2004).

The health care system does not have a niche into which PCOS fits. An e-mail correspondence with the medical director of the Center of Excellence in Women's Health $(\mathrm{CoEWH})$ at a large eastern health science center also supports the patient perceived need for this project. The e-mail is as follows, "One of my patients recently pointed out that it is a disease without a home after she had been put off by several providers who did not feel competent to address it." (Davisson, personal communication, March 19, 2008). In personal discussions with this author, three young women under 22 years of age stated that in their experiences, none of their health care providers had ever explained what PCOS is or the range of potential health problems it causes, nor did these providers discuss how PCOS could affect their lives.

\section{Diagnosing and Treating Chronic Illness}

Almost half the population of Americans, 133 million people, lives with a chronic condition (Partnership for Solutions, 2004). A chronic health care condition is any condition that 
requires management by the affected person and interface with a health care system. For the best outcome for patients suffering with a chronic disease, the management plan should involve both the provider and the patient in actively managing the disease (Wagner, Austin, \& Von Korff, 1996a, 1996b). PCOS is a chronic health care condition that should be managed daily by the patient with support from health care providers. The management plan needs to focus on obtaining and maintaining an optimum state of health (Wagner, et al., 1996a)

Traditional primary care systems are not designed to meet all the needs of a patient with a chronic illness. Problems in a traditional primary care system affecting the quality of care for patients with chronic illness include: 1) rushed practitioners either not aware or not following established care guidelines, 2) lack of care coordination due to the number of providers working in a given care site, 3) lack of active patient follow-up, and 4) patients not appropriately trained to manage their illness at home (Wagner, et al., 1996a, 1996b).

Many primary care systems focus on treating episodic or acute occurrences of illness. The system, itself, reacts to delivering the care being requested by an ill person seeking care. The free health care clinic in WV in which this project is based operates in this reactive mode. One reason this occurs is because the clinic is staffed by clinicians who donate small amounts of their time. Only mid-level providers staff the clinic full time. With this pattern of staffing, continuity and coordination of care are often compromised. Patient's return or follow-up visits are often with a different provider than was the initial visit. These factors tend to support a traditional reactive approach to care. While PCOS is a common endocrine disorder in women, it is not one of the problems commonly expected to present to primary care clinics. This fact and the varied expertise of health care providers in the clinic may contribute to initially missing the diagnosis of PCOS and less than ideal care being initiated (Gandhi, et al., 2006). 
PCOS Project 6

In a systematic review of the literature, Azziz, et al. (2005) estimated approximately 4 million women in the United States (U.S.) have PCOS. When comparing percentages of women with PCOS by region of the country, the greatest percentage, $34.72 \%$, live in the Southern region of the U. S., which includes West Virginia (Health Care and Utilization [HCUP], 2005). The 2005 census reports 352,442 women of reproductive age, between the ages of 18 and 44, are living in W.V. (U.S. Census Bureau, 2006). Because 5\% to $10 \%$ of women of reproductive age suffer from PCOS, one can estimate that 17,622 to 35,244 women in this state are living with PCOS.

\section{Theoretical Framework}

In an effort to address the health problems encountered in traditional primary care, Wagner (1998) developed a Chronic Care Model (CCM). This model focuses on primary health care system changes that are better able to manage patients with chronic conditions (Wagner). These system changes include a nontraditional care approach for the provider, staff, and patient.

Studies reporting improvement in outcomes for various chronic illnesses support the choice to use CCM to guide the development of this project. Bodenheimer, Wagner, and Grumbach (2002a) performed a systematic review of studies of diabetes care programs that included the CCM. They used the studies completed by the Cochrane review of ambulatory care diabetic management programs as the basis for their review. The evidence demonstrates that the CCM can improve the management of chronic conditions and reduce health care costs. Thirtytwo of 39 studies found that interventions based on successful management of chronic illnesses are CCM model components that improved at least one process or outcome measure such as hemoglobin A1C for diabetic patients. Eighteen of 27 studies discussing congestive heart failure, asthma, and diabetes demonstrated reduced costs or lower use of health care services to manage 
disease (Bodenheimer, et al., 2002a). A study that exemplifies the effective use of CCM is a randomized control trial performed in Denmark that focuses on primary care disease management for diabetics (Zoffman, Harder, \& Kirkevold, 2008). Patients were randomized to a usual care group, or to an intervention group that provided decision support, regular follow-up, reminder systems, and self-management support based on individualized goals. After six years, the intervention group had significantly lower hemoglobin A1C, blood pressure and cholesterol levels. This outcome supports the premise that use of the CCM is effective in primary care for managing patients with chronic diseases. Other studies adopting CCM as the approach to treat chronic illnesses such as cardiovascular disease, congestive heart failure, chronic obstructive pulmonary disease, and depression report better patient outcomes than traditional models (Adams, et al., 2007; Feifer, Ornstein, Nietert, \& Jenkins, 2001; Stroebel, et al., 2005). A pilot study by Stroebel et al. found the CCM was a useful guide for structuring the delivery of effective chronic disease management for patients receiving care at a free clinic.

PCOS is a life-long condition with long-term complications. CCM offers a structure under which chronic conditions are managed successfully using a prevention- based approach as opposed to the traditional system that focuses on addressing acute care issues as they arise (Bodenheimer, Wagner, \& Grumbach, 2002b). These studies identify that use of the CCM to develop a strategy for managing a chronic syndrome such as PCOS can be successful. This proposed project, dubbed "The PCOS Project", will be based on the elements of CCM.

Patients living with a chronic illness require different types of interaction and have different needs from a health care system than can be met in an acute care focused primary care system. The chronic care model was designed by the MacColl Institute for Healthcare Innovation 
to reshape primary care systems to better meet the health care needs of those living with a chronic illness (Wagner, 1998).

\section{The Chronic Care Model}

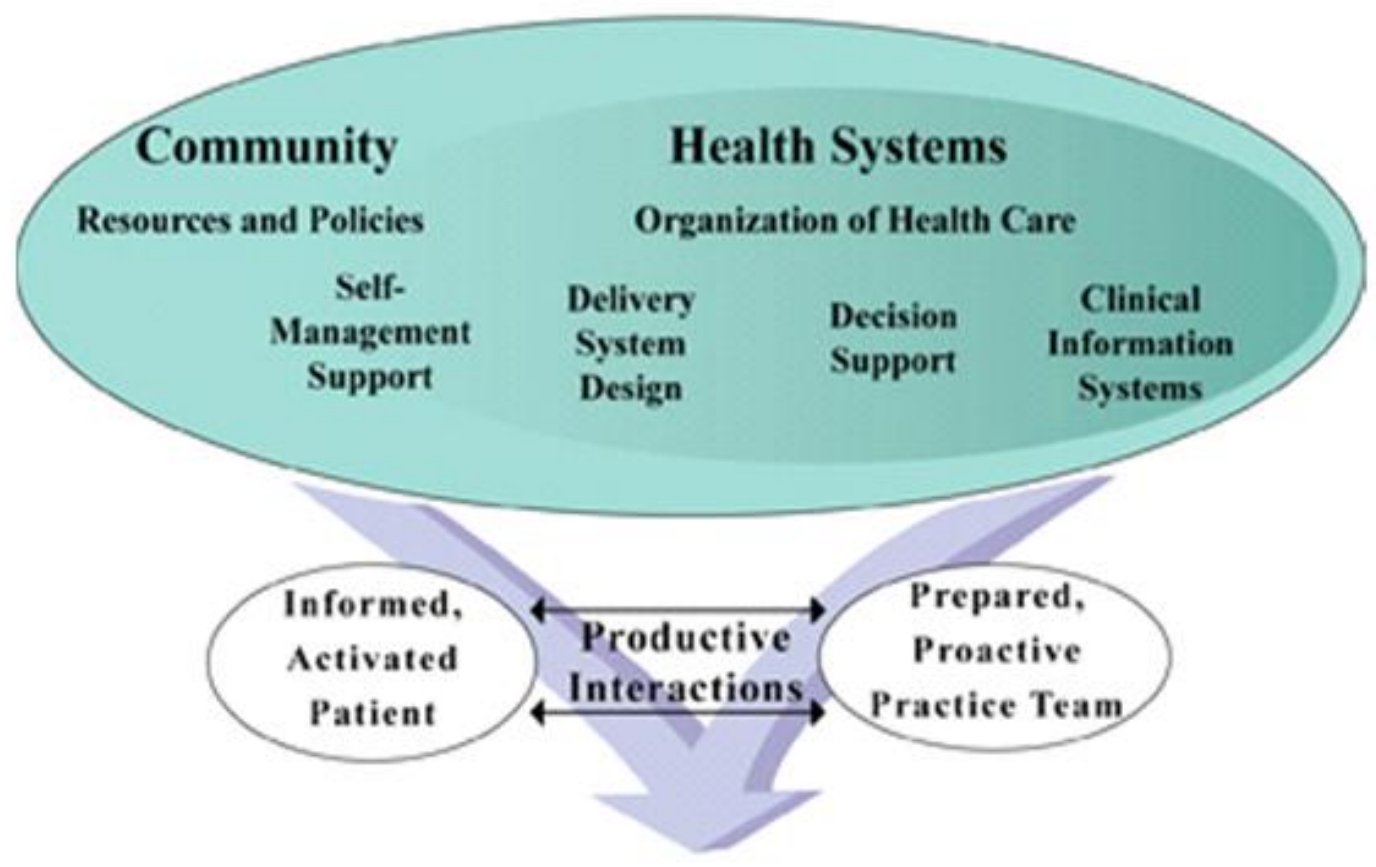

\section{Improved Outcomes}

Developed by MacColl Institute $\&$ ACP-ASM Joumals and Books

The model is based on the successful interaction of an informed, activated, and empowered patient having productive interactions with a prepared proactive team. An informed activated patient is defined as a patient who seeks knowledge, is actively involved in self care, and is an active participant in the decision making about his or her own care with the health care providers. The model identifies six elements that are essential to bring about the productive interactions between the provider team and the activated patient in order to improve outcomes. These elements are also essential to creating the informed activated patient and the prepared proactive team. The elements are: community involvement, health system leadership support, 
PCOS Project 9

self-management support, delivery system redesign, decision support, and clinical information systems (McCulloch, Price, Hindmarsh, \& Wagner, 1998; Von Korff, Gruman, Schaefer, Curry, \& Wagner, 1997; Wagner, et al., 1996a; Wagner, et al. 1966b). When the six elements occur in the clinical setting, the result is improved patient outcomes for patients living with a chronic illness.

\section{Literature Review}

\section{Chronic Care Model}

More than half of patients with a chronic illness have multiple health problems that require attention at each health care visit. As the number of patients with a chronic illness diagnosis increased, Wagner, et al. (1996a) developed the CCM to correct the deficiencies of usual care systems to meet this group of patients' needs. The CCM is a set of concepts that focus on the infrastructure of ambulatory care systems to improve health care response to the needs of patients with a chronic illness. The concept of the model is to change from a reactive to a planned and proactive approach to managing chronic illnesses. CCM describes a reconfiguration of the ambulatory health cares system that shifts from acute episodic visits to planned, routinely scheduled visits that focus on function and prevention of exacerbations and complications (Wagner, 1998).

The CCM model identifies elements of the health care system that lead to improved outcomes for individuals with a chronic illness. The six essential elements of the CCM are: the community, the health system, self-management support, delivery system design decision support, and clinical information systems. The community element encourages the use of community resources to meet the needs of patients and eliminates duplication of available services. The health system element focuses on creating a culture and organization of care that 
promotes safe quality care. Self-management support places emphasis on the patient's role in managing his/her health through empowerment and education (Bodenheimer, 2005; Von Korff, Gruman, Schaefer, Curry \& Wagner, 1997). Delivery system design assures the delivery of effective, efficient, clinical care and self-management support (Wagner, et al., 1996b). Decision support promotes clinical care that is consistent with evidence-based information and patient preferences (Wagner, et al., 1996b). Clinical information systems organize both patient and population information to facilitate efficient and effective care (Wagner, 1995). The combination of these elements improves satisfaction and health outcomes of patients with chronic illnesses.

The Robert Wood Johnson Foundation authorized an independent evaluation of the CCM process for those health systems adopting the model. The evaluation team included members of the RAND Corporation (1999) and researchers from the University of California at Berkeley. This team evaluated 51 participating sites involving approximately 4000 patients with diabetes, congestive heart failure, asthma, and depression. The evaluation identified improvement in the element areas of the model. Patients with diabetes had a significant decrease in cardiovascular disease risks. Congestive heart failure patients were more knowledgeable, more frequently stayed on recommended therapy, and had 35\% fewer hospital days. Patients with asthma and diabetes were more likely to receive appropriate therapy. Details of these findings are available through the RAND „Health Program Improving Chronic Illness Care Evaluation'. As PCOS is a chronic health condition, improvement in patient health outcomes and satisfaction with the health care system would be expected after application of CCM.

\section{Missed or Delayed Diagnosis}

A limited number of studies exist that address the effect of continuing health care education in preventing missed or delayed diagnoses. Most studies address specific diagnoses 
and not the topic of continuing education and changes in diagnosis or disease management changes. The following studies were found to support continuing education and practice changes that improve diagnosis and care.

Gandhi, et al (2006) conducted a retrospective review of 307 closed malpractice claims in which the alleged error was a missed or delayed diagnosis in the ambulatory setting. The purpose of the review was to develop a framework for investigating missed and delayed diagnoses, advance understanding of the cause, and identify opportunities for prevention. The most common errors ( $85 \%$ ) occurred in a physician's office, and the primary care physician was the provider most commonly involved.

The predominant reason found for a missed diagnosis was failure to order an appropriate diagnostic test followed by a failure to create a proper follow-up plan. Lack of knowledge of appropriate testing was the most common reason given for failure to order a diagnostic test. Other common errors causing a missed diagnosis in non cancerous diseases were delays by patients in seeking care, taking an inadequate history or physical exam, and failure to refer (Gandhi et al, 2006; Singh, Thomas, Myrna, \& Peterson, 2007).

The factors attributed to a missed or delayed diagnosis were failures in judgment, decrease in vigilance or memory, lack of knowledge, patient-related factors, and not performing a physical exam. Although the study examined multiple, significant causes of breakdown in either the system or the diagnostic process, human error was present as well. The human errors identified were reliance on the physician's knowledge or memory to ensure the correct test is ordered and poor communication strategies in the clinic setting. A patient-related factor of having complex disorders was also a reason associated with delayed or missed diagnosis (Gandhi et al, 
2006). The conclusion of a study by Guradini, Talamini, Fiorillo, Lirutti, and Palese (2008) was knowledge is progressively lost if refresher courses are not held on a regular basis.

Recommendations from Gandhi, et al. (2006) include changing the systems to alleviate the cognitive errors by reducing dependence on memory for appropriate testing and clinical diagnosis. Errors associated with follow-up and further evaluation can be decreased by forcing consideration of evidence-based diagnostic plans or second opinions. Gandhi et al (2006) also noted that for changes to have a maximum effect they must be easy to use and easily integrated into the workflow. For example incorporating clinical decision-making support, appropriate testing for diagnosis and appropriate follow-up in an electronic medical record will decrease missed or delayed diagnoses.

Davis, Thomson, Oxman, and Haynes (1995) conducted a systematic review of studies on education strategies and interventions that assessed physician performance and health care outcomes. For this study, educational intervention was defined as any attempt to persuade physicians to modify their practice performance. Three quarters of the studies reviewed $(n=75)$ were conducted in outpatient settings. They found that a physician reminder was an effective single-method intervention to yield an effective practice change. Other studies found that success in changing performance included reinforcing methods such as feedback or reminders. Barriers to change included: individual readiness to change, decreased motivation to change, a knowledge problem, or no perception of a gap between current knowledge and skills and knowledge needed to bring about the practice change. Knowledge deficit and memory loss over time are significant contributors causing missed or delayed diagnosis. Continuing education sessions or refresher sessions are one way to change the incidence of a missed or delayed diagnosis. Reminder systems such as electronic records that prompt reminders for providers are a way to positively 
PCOS Project 13

effect change in both diagnosis and management of patients. Based upon the findings of these studies an educational update and use of electronic prompt system should improve diagnosis and consistency in management of PCOS.

\section{Definitions of PCOS}

Several definitions of PCOS have been proposed in an effort to encompass women with a range of mild to more severe symptoms. In 1990, the National Institute of Child Health and Development (NCIHD) convened a consensus conference to define the diagnostic criteria for PCOS. Despite variability in opinions, the diagnostic criteria arising from the NIH conference, include women who have both chronic anovulation and evidence of androgen excess for which there is no other cause (Guzick, 2004).

The European Society for Reproduction and Embryology and the American Society for Reproductive Medicine (Rotterdam consensus group) held an international consensus meeting in Rotterdam, Netherlands in 2003. The goal of this group was to create diagnostic criteria to define and diagnose PCOS. Although total agreement was not reached, the consensus of the Rotterdam group defined the diagnostic criteria as a woman who has at least two of the following three features present: (1) oligomenorrhea/amenorrhea, (2) clinical or biochemical signs of androgen excess, and (3) polycystic ovary by ultrasound scan, for which there are no other causes (Rotterdam ESHRE/ASRM-sponsored PCOS consensus workshop group, 2004). Use of the Rotterdam criteria incorporates many women with PCOS who would have been missed by NCIHD criteria, thus increasing the prevalence to nearer $10 \%$.

In an attempt to resolve the differences between the two accepted definitions, the Androgen Excess Society (AES) task force performed a systematic review of medical literature to compose a judicious definition of PCOS (Azziz, et al., 2006). They concluded that the 
original 1990 NCIHD criteria should be accepted as the definition of PCOS with some modifications. Taking into consideration the opinion from the Rotterdam group, the AES task force identified nine different phenotypes that could be could be used as criteria in diagnosing PCOS based on the current knowledge. The nine phenotypes are: 1) hyperandrogenemia, 2) hirsutism, 3) oligoanovulation, 4) polycystic ovaries, 5) combination of chronic anovulation and androgen excess, 6) combination of oligomenorrhea/amenorrhea, clinical or biochemical signs of androgen excess and polycystic ovary by ultrasound scan, 7) oligomenorrhea/amenorrhea, 8) impaired glucose tolerance/insulin resistance, and 9) metabolic syndrome (Azziz, et al.)

AES defines PCOS as a disorder of androgen excess with an ovarian etiology and/or consequences after exclusion of other known androgen disorders (Azziz, et al.). The absence of clinical or biochemical indicators of excess androgen in women under the age of 40 with other PCOS phenotypes makes the diagnosis of PCOS less certain (Azziz, et al.). Thus, three accepted definitions of PCOS exist in health care (Azziz, et al., 2006; Guzick, 2004; The Rotterdam ESHRE/ASRM-Sponsored PCOS consensus workshop group, 2004).

\section{Etiology and Pathophysiology of PCOS}

PCOS is the most common endocrine disorder of women, yet the etiology and pathophysiology remain unknown. Defects in the reproductive endocrine pathways create a cycle of abnormal hormonal secretions that cause the range of observed phenotypes. Many theories have been proposed. They include 1) a complex genetic defect, 2) a defect in insulin action and secretion causing insulin resistance and hyperinsulinemia, 3) a defect of androgen synthesis that leads to enhanced ovarian androgen production, or 4) a neuroendocrine defect causing an exaggerated lutenizing hormone (LH) pulse and frequency, causing excess adrenal androgen 
production (Tsilchorozidou, Overton \& Conway, 2004). Each of the theories is based on what the theorist identifies as the primary defect causing the self-perpetuating cycle of abnormalities.

The etiology is not clearly understood but studies suggest a genetic (autosomal-dominant) component. PCOS is found predominantly in families. Studies attempting to define the specific genetic cause suggest that PCOS is a complex multigenic disorder. The clinical and biochemical presentation is influenced by environmental factors as well (Abbott, Dumesic \& Franks, 2002; Diamanti-Kandarakis \& Piperi, 2005). Based on animal studies, Abbott, et al. suggests that PCOS is a linear process that begins in utero. They postulate that either or both hyperandrogenic fetal ovaries or the hyperandrogenic adrenal cortex are the cause of excess fetal androgen production beginning in the second trimester. Androgens are potent gene transcription factors and induce other critical transcription factors effecting gene expression. This implies fetal androgen excess in female fetuses may reprogram coding in multiple organ systems that will later appear as the varying phenotypes of PCOS (Abbott, et al.). Though not proven, there is evidence to support the idea that a genetic defect causes the fetal ovary theca cells to over produce androgens causing the cascade of changes in utero that lead to the syndrome (Urbanek, et al., 2006).

The cause of insulin resistance (IR) and hyperinsulinemia remain uncertain. Abnormalities in post-insulin signaling and abnormal insulin secretion have been identified in women with PCOS. The insulin-signaling defect in adipocytes and skeletal muscle is specific to PCOS. IR in PCOS occurs by a different mechanism than in women who are obese or have type 2 diabetes mellitus without PCOS (Corbould, Zhao, Mirzoeva, Aird \& Dunaif, 2006). Androgens are believed to contribute to peripheral insulin resistance in PCOS by acting directly on the insulin-signaling pathways (Diamanti-Kandarakis, 2008). 
Sixty to $80 \%$ of women with PCOS have hyperandrogenemia (Diamanti-Kandarakis, Papiliou \& Palimeri, 2006). The over production of androgens by theca cells is a response to increased stimulation of the ovary by LH. Theca cells in women with PCOS more efficiently convert androgenic precursors to testosterone than do normal theca cells (Ehrmann, 2005). Follicle-stimulating hormone (FSH) is responsible for regulating aromatase activity of the granulosa cells. The level of FSH determines the amount of estrogen that is made from androgen precursors (Ehrmann). FSH levels are often decreased in PCOS (Ehrmann; Marrinan, \& Stein, 2007).

Insulin is both a direct and indirect contributor to hyperandrogenemia. It acts synergistically with LH to enhance theca cell androgen production. Hepatic synthesis of sex hormone-binding globulin (SHBG) is inhibited by insulin. Elevated levels of insulin decrease SHBG so it is not available to bind with testosterone, thus increasing circulating levels of free testosterone (Ehrmann, 2005). The increased androgens also inhibit the production of SHBG (Marrinan, 2007). Elevations of free testosterone cause worsening clinical signs of hyperandrogenism. Higher androgen levels contribute to central/android obesity, which increases insulin resistance and worsening PCOS symptoms (Azziz, et al., 2005; Ehrmann).

Normal menstrual cycles occur when the hormone levels and feedback pathways of the hypothalamic-pituitary-ovarian axis function appropriately. In PCOS, the hypothalamicpituitary-ovarian axis is disturbed. The defect that causes this disturbance is unknown. There is thought to be an abnormality of the gonadotrophin-releasing hormone pulse generator of the hypothalamus. It is unclear if this defect is primary or secondary (Marx \& Mehta, 2003). Elevated LH levels and normal or decreased FSH are found in PCOS. Also, increased levels of free estrogen, primarily in the form of estrone and estradiol are found. Elevated estrogens cause a 
PCOS Project 17

feedback effect on the pituitary that leads to further suppression of FSH and increased frequency and amplitude of pulsating release of LH. This hormonal environment increases the production and release of androgen precursors by theca cells. These androgen precursors are converted peripherally to primarily estrone, which in turn enhances the feedback to the pituitary perpetuating the cycle of elevated $\mathrm{LH}$, decreased $\mathrm{FSH}$, and increased androgen production culminating in abnormal menstrual cycles and hyperandrogenemia (Ehrmann, 2005; Marrinan \& Stein, 2007).

\section{Clinical Consequences of PCOS Pathophysiology}

Early detection of health status changes is an important part of the prevention plan. Prevention or delay of progression of PCOS involves ongoing secondary prevention aimed at early disease detection, thereby increasing opportunities for interventions to prevent progression of the disease and emergence of symptoms. Prompting providers to order recommended surveillance screenings is built into HealtheWV charting program. Electronic patient record systems that alert providers when recommended screening tests are due are important for increasing consistency in managing a chronic illness and improving patient outcome. Potential sequelae resulting from pathophysiology are included in both the educational offering and in the electronic chart generated plan. The consequences of PCOS are the foundation for the development of the program template. Each potential health threat from PCOS is described in the following sections of the paper, as it will be incorporated into the educational program and into the electronic charting program template.

\section{Endocrine and Gynecological}

Thirty to $40 \%$ of women with PCOS have impaired glucose tolerance. Type 2 diabetes mellitus will develop in 10 to $45 \%$ of women with PCOS by the time that they reach their forties. 
Obesity is present in over $50 \%$ of women with PCOS. Insulin resistance and hyperinsulinemia are common findings in both obese and non-obese women with PCOS. Independently, obesity also leads to insulin resistance. Therefore, obese women with PCOS have two contributing factors causing them a greater degree of insulin resistance than non-obese women with PCOS (Tsilchorozidou, et al., 2004). Endocrine disturbances in PCOS lead to increased blood pressure, increased low-density lipoprotein (LDL) cholesterol, and decreased high-density lipoprotein (HDL) cholesterol. These are known significant risk factors for developing cardiovascular disease and metabolic syndrome (Ehrmann, 2005; Sheehan, 2004). Elevated androgens cause hirsutism in $60 \%$, acne in $15 \%$ to $25 \%$, and androgenic alopecia in an estimated $5 \%$ of women with PCOS. Hirsutism is a most reliable index for elevated androgens. AES states PCOS cannot be diagnosed without either clinical or biochemical evidence of hyperandrogenism (Azziz, et al., 2006).

\section{Psychosocial Sequelae}

In Snyder's (2006) study, women with PCOS recognized themselves as different from other women without the disease. Higher than average weight gain, lack of regular menstrual cycles, heavy or continuous bleeding with occasional menses, growth of excessive unwanted facial and body hair, and severe mood swings were identified as the characteristics that made PCOS sufferers feel different. They also expressed that feeling different from other women created a sense of insecurity and isolation (Snyder). The study participants stated that hirsutism and infertility problems made them feel less feminine as though womanhood had been stolen (Kitzinger \& Wilmot, 2002; Snyder).

Obesity also contributed to a sense of being not normal or not looking like the media portrayal of femininity (Snyder, 2006). Women with PCOS define a normal female as one who 
PCOS Project 19

looks more female (without hirsutism), possesses a beautiful complexion, and has regular menstrual cycles (Snyder). A 1998 study by Cronin, et al. of 100 women with PCOS found while some women were concerned about irregular menses and infertility, weight or hirsutism caused a greater negative impact on their quality of life.

There is an association between obesity in young girls and PCOS. Childhood obesity may be the initial symptom of PCOS (ACOG, 2006). Trent, Rich, and Austin (2002) using a health related quality of life (HRQoL) inventory determined that adolescent girls with PCOS selfreported a statistically significant reduction in general health perceptions, behavior, physical function, and family activities compared to adolescent girls without PCOS.

\section{Cancer Risks}

Endometrial hyperplasia, as well as endometrial, ovarian and breast cancer are associated with PCOS. The endometrial hyperplasia and cancer are attributed to the continuously estrogen stimulated endometrium that goes unopposed by progesterone due to anovulation. Endometrial cancer is also associated with obesity and type 2 diabetes mellitus, which is prevalent in women with PCOS (Hardiman, Pillay, \& Atiomo, 2003). Determining the cause of the increased prevalence of breast and ovarian cancer is difficult. Obesity, anovulation, and infertility are independent risk factors associated with breast and ovarian cancer, and they are common problems in PCOS (Balen, 2001).

Sleep Apnea

An increased prevalence of obstructive sleep apnea that cannot be explained by obesity alone has been found in women with PCOS. A study by Fogel, Malhotra, Pillar, Pittman, Dunaif, and White (2001) found that, after controlling for body-mass index (BMI), the risk of sleepdisordered breathing was increased by a factor of 30 . Fogel, et al. determined that insulin 
PCOS Project 20

resistance seems to be a stronger predictor of sleep-disordered breathing than age, BMI, or elevated free testosterone.

Infertility, High Risk Pregnancy, and Potential Delayed Lactogenesis

A common reason why women with PCOS seek care is infertility. Anovulation is a hallmark of the disorder. Anovulation is due to the increased number and the disturbed maturation of recruited ovarian follicles resulting from androgen excess, increased LH, and decreased FSH stimulation of the ovary (Diamanti-Kandarakis, 2008; Diamanti-Kandarakis, et al., 2006). Women with PCOS who desire pregnancy are usually referred to a gynecologist or reproductive endocrinologist for infertility treatment. Obesity is a factor that contributes to infertility. Increasing body mass index (especially $>35$ ) yields a decrease in fecundity (Legro, 2007).

There is conflicting evidence about the increased risk of early spontaneous pregnancy loss in women with PCOS. The role of obesity as a cause of early pregnancy loss is a confounding, independent risk factor. Early pregnancy loss is associated with hyperinsulinemia, which is present in both obese and non-obese women with PCOS. It is thought that reduced insulin sensitivity may cause an endometrial inflammation reaction, which prevents implantation and leads to early pregnancy loss (Siassakos, \& Wardle, 2007).

Antenatal complications associated with PCOS include: impaired glucose tolerance, gestational diabetes mellitus, pregnancy-induced hypertension, and pre-eclampsia. Iatrogenic premature births and increased rates of cesarean births are also associated with PCOS (Marx, \& Mehta, 2003; Siassakos, \& Wardle, 2007). A postnatal complication for large babies of obese women is the tendency to become obese adults. There is concern that in utero fetal programming 
PCOS Project 21

of growth hormone and insulin growth factors may influence postnatal growth and insulin sensitivity of individuals (Siassakos, \& Wardle).

Endocrine issues such as polycystic ovary syndrome can affect milk production. Case studies by lactation consultants report some women with PCOS who have successfully become pregnant and successfully initiated breast feeding. However, such women are often unable to produce a sufficient volume of milk to nourish a growing infant (Amir, 2006; Betzold, Hoover, \& Snyder, 2004). Although some women with PCOS have no problem breastfeeding, there appears to be a group of women with PCOS who have underdeveloped mammary tissue that cannot produce an adequate milk supply (Marasco, Marmet, \& Shell, 2000). Amir noted that the inability to successfully lactate may be related to hormonal imbalances or increased serum androgen levels. Elevated androgen levels are associated with decreased breast cell proliferation and lack of sufficient breast tissue development to maintain milk production. The causes of delayed or failed lactogenesis II result from one of many endocrine errors or insufficient mammary tissue (Betzold, et al.; Marasco, et al.).

Opportunities for the Project

The clinical setting in which the project was implemented provided opportunities that support the initiation of such a project. The clinic offers services to adults who have no insurance and meet certain income guidelines. The income guidelines are based on family size and living on a gross salary at or below $150 \%$ of the poverty level. This clinic depends on a variety of physicians and midlevel providers, who receive either minimal reimbursement or who volunteer their time free of charge, to provide care for this population of patients. Over time, patients do not see the same provider or group of providers on a consistent basis, so continuity of care is not 
PCOS Project 22

always possible. Despite the limitations of the free clinic, the goal of this clinic is to deliver quality care for its clients.

The clinic acquired an electronic medical record system from HealtheWV, which includes electronic note charting and chronic disease templates that remind health care providers to order required tests to monitor the health status and patient response to therapy. For the proposed project, the project manager (this author) proposed development of an evidence-based electronic PCOS patient management and charting template, which could be incorporated into the electronic system. The goal is for the HealtheWV electronic system to assist providers to provide consistent, evidence based, high quality care for women with PCOS. It was proposed that when a diagnosis of PCOS is made, an evidence-based management plan would be generated by the HealtheWV electronic system, following the same computer generated format used for other chronic diseases. This computer capability should improve the consistency of management plans for therapies and required health care surveillances, which are expected to improved outcomes over a life time for women with PCOS.

\section{Congruence with Organization's Strategic Plan}

This project encompasses a holistic health care approach to the diagnosis and management of a serious chronic disorder that affects the health of a significant portion of women in WV and in the United States as a whole. The PCOS project is compatible with the mission of the free clinic to improve the health and well being of non-insured, lower income women in WV through education and health care. The PCOS project focuses on prevention of negative health sequelae secondary to a chronic health problem for women who lack the financial resources to obtain this level of health care in the traditional health care system. Women from Appalachian cultures tend to place the needs of their families before their own health; 
PCOS Project 23

therefore, they are less engaged in preventive health care (Patton, 2005). First line therapy for PCOS includes life style changes and preventive care that require support from health care systems (Kovacs, 2006).

\section{Project Description}

An in-depth review of the literature relevant to PCOS was completed and the evidencebased recommendations were organized into a diagnostic guide and management plan prior to implementing the two part project. The first aspect of the project focused on improving the diagnosis of PCOS at a free primary care clinic. An educational session was conducted during the quarterly provider staff meeting at the clinic. Accepted definitions used to identify the diagnostic characteristics and symptoms that are present in women with PCOS were emphasized. A list of both primary and secondary PCOS symptoms that should prompt the provider to consider PCOS as a differential diagnosis for women with such symptoms was described. A brief review of pathophysiology was included to enhance provider understanding of the complexity of the biochemical interactions and feedback pathways of this endocrine disorder. Understanding the complex pathophysiology should enhance the provider's ability to diagnosis PCOS early as well as increase his or her understanding of the importance of early intervention.

An evidence-based patient management guide was created and incorporated into the HealtheWV electronic patient management system for providers to help them manage or prevent the wide variety of sequelae that can result from PCOS. HealtheWV is an electronic patient record system that enables chronic illness management plans to be pre-programmed into the system. When a patient is diagnosed with a chronic illness, the system will prompt the provider to order selected screening tests specific for the diagnosis. This system also prompts the provider as to which and when routine health maintenance surveillance tests are due. 
PCOS Project 24

\section{Project objectives}

The objectives are:

1. To provide an educational session at a free clinic to increase providers' knowledge about diagnosing PCOS;

2. To assess health care providers' knowledge about PCOS and its management before and after an educational session;

3. To develop a management plan and imbed the plan in an electronic patient record system at the free clinic to improve efficiency and quality of care for PCOS management;

4. To evaluate the effectiveness of an electronic management plan in increasing the frequency of diagnosis, and appropriateness of treatment of PCOS at the free clinic. Project Design

\section{Timeline}

The project was initiated in August 2008 and continued through 2009. For a step-by-step timeline please see Appendix A.

\section{Resources}

There is minimal expense to the free clinic. HealtheWV system has templates for other common chronic illnesses currently in place. The electronic charting system is a recent acquisition of the clinic. By designing the PCOS template at this time, no technician salary cost will be incurred to assist the project manager in loading the data and creating the pathways that signal the care provider as to which tests to order if indicated for the diagnosis, and when recommended health screenings are due. 
PCOS Project 25

Cost savings for patients and the health care clinic will require a cost analysis to determine savings created by decreased expenditures arising from sequelae and/or hospitalizations for problems that can be avoided through timely diagnosis and appropriate management of PCOS. However, the cost analysis should not be performed until the project has been implemented for an extended period of time that will be determined. Cost analysis will not be a part of this project. Patient care satisfaction for women with this disease is anticipated to improve, as they perceive a health care system that is responsive to the specific issues associated with PCOS.

Budget

The budget to implement the PCOS project is included in Appendix B.

\section{Evaluation}

PCOS is a women's health issue that is currently under diagnosed. When PCOS is diagnosed, consistency in initiating management and recommending surveillance plans for secondary prevention of the complications of PCOS often does not occur. A consistent evidencebased plan is essential to delay or prevent the multiple health problems that can occur in women with PCOS. It is essential for the health of this group of women that efforts are made to improve the diagnosis and management of this chronic endocrine disorder.

In association with an educational session, both a pre- and posttest knowledge assessment about diagnostic criteria and laboratory testing were completed with providers at the free clinic (Appendix C). Such testing indicated whether learning had taken place and can serve as indicator about the effectiveness of the education strategy. The clinic at which the project was conducted has quarterly provider meetings. The agenda for the provider meetings includes a time slot for continuing education. The PCOS educational session was presented at the May meeting. 
PCOS Project 26

A PowerPoint presentation along with a question and answer opportunity was offered (Appendix D).

To assess their prior knowledge about PCOS, a tool developed by this author was completed by the providers. After providing an educational session that included a question and answer session, the same tool was used to determine if providers' knowledge had improved. Knowledge acquisition was assessed by using a matched sample t-test to compare the difference in means between the two sets of test scores.

A PCOS management template was developed by the Project Director (Appendix E) and incorporated into the clinic's electronic patient data system to be utilized by providers. A chart review was conducted before the template was made available and again 3 months after the PCOS management template was loaded into the HealtheWV electronic patient management system. The chart review was intended to determine whether providers evaluate patients who present with abnormal menstrual cycles and/or clinical or biochemical symptoms of excess androgen for PCOS using the appropriate laboratory testing. The chart review noted whether an evidence-based plan was initiated at the time of diagnosis prior to the initiation of the electronic plan. Successful use of the electronic PCOS management plan for this project was defined by $30 \%$ or more of the patients diagnosed with PCOS having a management plan initiated in the HealtheWV system.

Three months after the education session, 50 charts of women presenting with abnormal menstrual cycles and/or clinical or biochemical symptoms of excess androgen were evaluated using the same criteria as the pre-intervention chart review. The post intervention chart review also added the question: Is the electronic PCOS management initiated. 
PCOS Project 27

Results

\section{Objective 1.}

The first objective was to provide an educational session. This objective was met on May 14, 2009. An educational information session (Appendix D) about diagnosis and long-term management of the health care of women with PCOS was presented at the provider staff meeting.

\section{Objective 2.}

Assessment of health care providers' knowledge about diagnosing and managing PCOS was the second objective. To measure the initial knowledge level and a change in knowledge after education, a pre-test and post test (Appendix C) were completed by each participant. The test consisted of five questions developed by the author. The questions were designed to evaluate the five learning objectives for the education session. The test questions were evaluated for clarity and correct content by an expert in women's health. The objectives for the educational session were:

1) The participant will be able to state the diagnostic criteria for PCOS,

2) The participant will be able to identify other causes of excess androgen that must be excluded,

3) The participant will be able to identify initial laboratory tests for diagnosis and

4) The participant will be able to name the risks associated with PCOS.

Because of the varying schedules and infrequency of providing services to patients at the clinic by some of the providers, the participants were asked to complete the pre and post test before and immediately after the session. Participants were asked not to provide any identifying information on the tests. Ten participants completed the pretest and demonstrated a mean 
knowledge score of 1.5 on a scale with a range of 0 to $5(\mathrm{O}=$ lower and $5=$ higher $)$. Eight participants completed the post test with a mean score of 4.25. Two providers at the session chose not to participate. Due to the small sample size, a Mann-Whitney test was used to determine whether there was a change in knowledge before and after the educational session. A significant change in knowledge $(p=.000)$ occurred as a result of the educational session. (See tables 1, Appendix E and table 2, Appendix F)

To assess specific areas of knowledge deficit the number of correct answers to each specific question on the pretest was calculated. The range of questions answered correctly was zero to three out of five total questions. Acknowledge deficit about PCOS existed for this group of providers. No provider was able to identify the three diagnostic criteria for PCOS. After the session, seven of eight (87.5\%) of providers correctly identified the three diagnostic criteria. At the pretest, one provider, out of $10(10 \%)$ identified other causes of hyperandrogenemia that must be excluded; and six of eight (75\%) at the post test could correctly identify other causes. Two providers out of $10(20 \%)$ identified the recommended diagnostic laboratory tests prior to the educational session, and six out of eight ( $75 \%)$ correctly identified the correct laboratory tests after the educational session. Five providers of $10(50 \%)$ could identify the potential risks associated with PCOS prior to the educational session and eight of eight (100\%) identified the risk factors correctly after the educational session. The first line therapy of choice was correctly identified by seven out of 10 providers ( $70 \%)$ prior to the session, and seven out of eight $(87.5 \%)$ after the educational session. Improvement in knowledge levels in the five areas identified by the learning objectives resulted from the educational session. (See figure 1, Appendix G) 
PCOS Project 29

\section{Objective 3.}

Due to limitations in current technology, an electronic provider prompt to consider PCOS as a differential diagnosis when symptoms are entered into the e-chart was not able to be embedded into the system. Due to software restrictions, a modified template (Appendix H), with a recommended health management plan for this chronic disease was created as part of the clinic's electronic charting system.

\section{Objective 4.}

To evaluate the effectiveness of an electronic management plan in increasing the frequency of diagnosis, and appropriateness of treatment of PCOS at the free clinic a pre and post chart review was completed. Five hundred and thirty- five charts of women cared for by the eight providers who agreed to participate in the study were reviewed for inclusion criteria. The inclusion criteria were patient charts with documented amenorrhea, abnormal menstrual cycles or abnormal or dysfunctional uterine bleeding, and with clinical symptoms of excess androgens. These clinical symptoms included hirsutism, acne, or alopecia. Thirty-four charts were found to meet the inclusion criteria. Since PCOS affects $5-10 \%$ of women of reproductive age, 34 out of the 535 charts meeting the criteria for inclusion represented an appropriate sample.

For data collection, two questions were posed. The first question posed was ,Are the appropriate diagnostic laboratory tests ordered?' The response was either yes or no. The criteria for a yes response for charts prior to the educational session included women who had a diagnosis of PCOS prior to admission to the clinic system, and those who had been diagnosed with PCOS using the conventional diagnostic testing that was the standard of care at the time of diagnosis. Conventional diagnostic testing include: lutenizing hormone levels, follicle stimulating hormone levels, thyroid stimulating hormone levels, total testosterone levels, fasting glucose levels, and an 
insulin level. Evidence-based studies currently recommend a prolactin level, thyroid stimulating hormone level, total testosterone levels, and 17 hydroxyprogesterone level for initial diagnostic testing, and further studies can be added if indicated by the results of the initial findings. Of the 34 total charts, 31 charts met the criteria for inclusion prior to the educational session and three new charts entered the system after the educational session.

Three months after the educational session a chart review, using the same two questions was conducted to determine whether appropriate diagnostic laboratory testing was ordered when undiagnosed women presented with symptoms suggesting PCOS, as well as to determine if appropriate screenings were ordered for women already diagnosed with PCOS. Post education, 23 charts were available for review. Eleven of the 31 pre-educational charts were lost to follow up and three new charts entered the system. The 23 eligible charts were then further reviewed for documentation by the providers specifically noting if the appropriate diagnostic laboratory assessments, if indicated, had been ordered, and if the appropriate metabolic screening tests were obtained if they had not been performed within the year. The same questions were used to select charts for the post-educational review as had been posed in the pre- education chart review. 1) Were the appropriate diagnostic laboratory assessments performed when women presented with abnormal menstrual cycles and a clinical sign of excess androgen? (yes or no) 2) Were appropriate metabolic screen testing obtained if PCOS was diagnosed? (yes or no) Post educational session, the question about appropriate metabolic screen testing was answered yes if four studies, prolactin level, thyroid stimulating hormone level, total testosterone level, and 17 hydroxyprogesterone level were ordered, or the diagnosis of PCOS was made prior to the educational session $(n=23)$. If the diagnosis PCOS had been made prior to the educational session, one would not expect a second set of diagnostic laboratory tests to be ordered to 
diagnose PCOS again so those charts received a yes for appropriate diagnostic laboratory testing. Prior to the provider's educational session appropriate testing for diagnosis was found in 10 of 31 cases (32.3\% of the time). Post educational session appropriate diagnostic testing was found in 16 of 23 cases (69.6\% of the time). (See table 3, Appendix I and figure 2, Appendix J)

\section{Flow Chart for Patient Chart Selection}

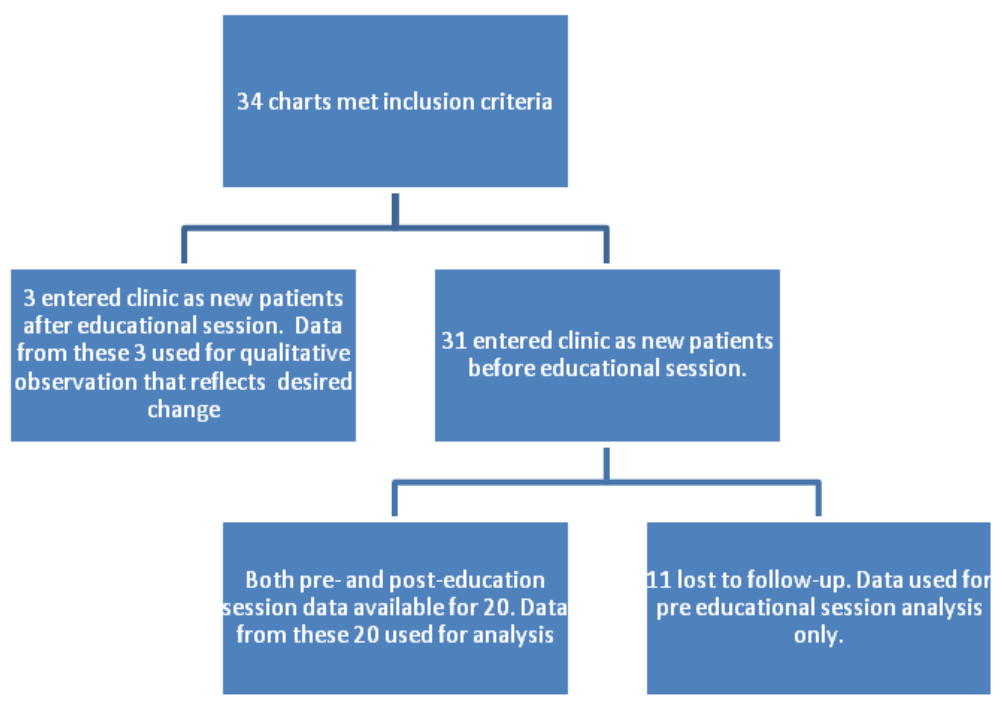

For the 20 cases present before and after the education session, a Pearson Chi-square was use to determine if there was a significant difference in providers ordering appropriate diagnostic tests three months after the educational session. A Chi-square test for independence indicated no significant difference in pre and post educational session for ordering appropriate diagnostic tests, $X^{2}(1, \mathrm{~N}=20)=.73, \mathrm{p}=.143$.

Prior to the educational session appropriate metabolic screening tests used as part of a chronic management plan were ordered in 20 of 31 cases (64.5\%) and post educational session such tests were ordered 19 of $23(82.6 \%)$ times. (See table 4, Appendix K and Figure 3, Appendix L).

For the 20 cases evaluated before and after the education session, a Pearson Chi-square was use to determine if there was a significant difference in providers ordering appropriate 
metabolic screening tests three months after the educational session. A Chi-square test for independence indicated no significant difference in pre and post educational session for ordering appropriate metabolic screening tests, $X^{2}(1, \mathrm{~N}=20)=.000, \mathrm{p}=1.000$.

Of the three new cases that presented with symptoms of PCOS, two had the appropriate diagnostic and metabolic screenings ordered by the provider. The third woman was referred to the women's health clinic within two weeks of her new patient visit for evaluation at the clinic.

\section{Discussion}

\section{Discussion of the project}

The Chronic Care Model served as the guide for this project. The model blends the community resources and policies with the organization of the health care system to improve patient outcomes. This project focused on the health care system's concept, and specifically the clinical information system's element. It is essential for the practice team to be prepared and proactive in the management of a chronic illness. In a busy clinic, utilization of technology and clinical information systems is especially efficacious when a team of providers cares for chronically ill patients. The use of electronic templates, which can provide care reminders, aids the healthcare team in providing timely and consistent care for a patient without relying on the memory of both the patient and the provider to follow a plan. The clinic, in which this project was staged, operates by using a team of primary care providers. The use of the electronic charting system has the potential to keep the team prepared and proactive in the care of women with PCOS. However the limited technology of the computer charting system and the inability to have the appropriate prompts for PCOS embedded does not assist the provider to remain proactive. This project does not support CCM being effective at this time. 
PCOS Project 33

\section{Discussion of the findings}

\section{Objective1.}

Twelve providers attended the quarterly provider meeting, which occurred as scheduled. Of the twelve providers present eight consistently provide primary care for women who attend the clinic. A discussion including questions and answers by participants occurred during and after the power point presentation. The eight providers who regularly manage the health care of women are included in the evaluation data. Three of the excluded members are sub-specialist and do not provide primary health care. The fourth excluded practitioner is new to the clinic and had not begun caring for patients until after initiation of the project.

\section{Objective 2.}

The decision to require the group to complete the post test immediately after the session was due to the dynamics of the group. The providers practice on a limited, part- time basis, from four hours per month to 8 hours per week, and on different days. It was determined that few providers would complete the post education questionnaire if the testing was not requested immediately after the education session because of the sporadic and part- time schedules of this groups of providers. Loss of data post-educational session with this small number of providers would affect the findings. Specifically for this reason, providers' knowledge was not tested again several months after the educational session. Testing of knowledge about PCOS at three or six months after the educational session would possibly show a no significant change from prior to the initial educations session due to the natural loss of knowledge over time (Davis, et al.1995).

Since PCOS is a common women's health problem, one can assume that this group of providers had obtained baseline knowledge about PCOS during their professional education. Yet, the provider's mean test score on the pretest was low and showed a significant 
improvement after the educational session indicating that their knowledge about evidence- based care for diagnosing and managing PCOS was deficient. Studies by Davis, et al. (1995) and Guradini, et al.(2008) support the need for refresher courses for providers to alleviate errors, which occur due to decrease in vigilance or memory, and/or lack of knowledge by providers. The educational session significantly improved the health care providers' knowledge about PCOS and its management. Refresher courses or continuing education sessions are required to prevent natural loss that occurs over time (Davis, et al.; Guradini, et al.) and should be offered at regular intervals.

Although testing was not performed to assess whether long term the knowledge about PCOS was retained, it is a positive finding that three new patients, with symptoms, who entered the system after the educational session, were either appropriately managed or were referred by the primary care provider to a woman's health provider to be evaluated for PCOS.

Diagnostic criteria and laboratory testing that is required to make a diagnosis of PCOS were the two areas of greatest knowledge deficit. A predominant reason missed diagnoses occur and there is a failure to create a long-term management plan is failure on the part of the provider to order appropriate diagnostic tests (Gandhi et al., 2006; Singh et al., 2007). Provider knowledge deficit and forgetfulness over time were identified by Gandhi et al. (2006) as major contributors to failure to order appropriate diagnostic testing. These studies support the finding that the greatest area of knowledge deficit for this group of providers is identification of diagnostic criteria and laboratory testing. Provider reminders were identified as an effective single-method producing effective practice change (Davis, et al., 1995). This new electronic system did not possess the technology necessary to provide a "pop-up" electronic prompt that would suggest differential diagnoses and diagnostic protocols when symptoms are entered into 
PCOS Project 35

the e-chart. Because the Healthe WV system could not provide diagnostic criteria, a guide to laboratory blood tests for diagnosis with the diagnostic values, and the recommended laboratoryscreening schedule was given to each provider participant as a laminated, pocket size card containing the information. Prior to the educational session, providers did know that the first line management for PCOS is lifestyle changes. Documentation of lifestyle changes is part of the selection menu in the plan section of the electronic chart that is used for each visit.

\section{Objective 3.}

An objective was to develop a management plan and imbed the plan in an electronic patient record system at the free clinic. Prior to starting the project, a discussion was held with the software developers of the electronic charting system about the possibility of developing a template for incorporating clinical decision making support, appropriate testing for diagnosis and appropriate follow-up. Both the software company and the clinic granted temporary administrative status to this author so the template for chronic management could be designed based on the current capability of this system (Appendix E).

Computer technicians designed the basic electronic patient record template with basic knowledge about the standard structure universally used to create a patient visit note. These developers were not health care or content experts. While this system is designed to allow for the development of templates that indicate the management for chronic illnesses, it does not have the capability to organize patient data into clinical algorithms, or suggest differential diagnoses for a set of signs and symptoms. Nor does this system allow for variations required to individualize a patient care plan from a standard care plan. Perhaps this is due to the limitations with current technology or the failure of software developers to understand and respond to this type of provider need in a busy clinic. The CCM has delivery system design, decision support, and 
clinical information systems as three of the six elements that are necessary in a health system to create a prepared proactive practice team, which lead to improved patient outcomes (McCulloch, et al., 1998; Von Korff, et al., 1997; Wagner, et al., 1996a; Wagner, et al. 1966b). Use of an electronic system that is sophisticated enough to suggest differential diagnoses based on symptoms could decrease missed or delayed diagnoses that occur from failures in judgment, cognitive errors due to dependence on memory, or lack of provider knowledge (Gandhi et al., 2006).

In designing the note template, selection of characteristics for the patient review of systems section and physical findings for the examination section were limited. Each e-chart section provides a choice of "other" and a pencil icon so the provider can type in any finding that is not on a drop down menu. There was not an option of adding the Ferriman and Gallwey hirsutism scale (Wild, Vesely, Beebe, Whitsett \& Owen, 2005). However, hirsutism, which was not on the general template prior to the project, was added as a selection on the drop down menu in the endocrine section of the review of systems. In the skin section of the physical exam area, the provider is able to select a face and body image on which areas can be identified with a typed in description of the finding from the physical examination.

The basic templates provided in HealtheWV do include appropriate screening intervals based on the U.S. Preventive Services Task Force (USPSTF) (2009) or other expert panel's recommendations for the population at large, and prompts for providers, which indicate that a surveillance screen or monitoring test is due. When development of the PCOS template began, it became evident that screening interval prompts in the e-chart could not be changed from the interval set by USPSTF for the general population to an appropriate interval for patients at high risk for developing a disease, or for chronic management if the specific disease existed. For 
example, screening intervals for lipid panels in the system are those recommended by USPSTF (2009) for a person who is not at risk and with normal values at their most recent screening. While frequency guidelines for lipid screening for women with PCOS are not specified, these women are at a greater risk for developing dyslipidemia. The software does not permit changes in the template to prompt providers to screen at closer intervals that should be considered for women with PCOS. While this does not prohibit the provider from ordering a surveillance test at a closer interval, a more frequent prompt option for the provider is not available. Without the closer interval prompts, screening is now dependent on the memory of the provider. The study by Gandhi et al. (2006) recommends changing systems to alleviate cognitive errors by reducing dependence on memory for appropriate testing and clinical diagnosis. Errors associated with follow-up and further evaluation can be decreased by forcing consideration of evidence-based diagnostic plans (Gandhi et al.). Perhaps as technology develops further the template can be adjusted to initiate closer interval prompts for patients at higher risk. A systematic review by Davis, Thomson, Oxman, and Haynes (1995) found that a simple reminder system is an effective single-method intervention to improve provider performance for clinical care.

The CCM upon which this project was designed, states that improved outcomes for people with chronic illnesses depend on productive interaction between informed patient and prepared proactive provider team. Having a template that prompts providers about the ongoing plan of care helps them to remain proactive. By sharing the plan of care with the patient, the patient becomes informed and can become self-directing in managing his or her health plan.

\section{Objective 4}

Although a management template for PCOS exists in Healthe WV system, the clinic system's current method of template selection for a patient visit does not allow the provider to 
select a specific template for charting. As patients arrive for a health care visit, they are registered and then initially evaluated by a medical assistant. Thus the medical assistant is the person who selects the note template when commencing the visit note, not the provider. The medical assistant may not be aware of the diagnosis or purpose of the visit unless the patient tells them. Often the purpose of the visit or a diagnosis may change after further patient evaluation by a provider. It is not a simple task to change the template during the visit after the management template is initiated by the medical assistant. The patient's vital signs and any notes made by the nursing staff do not automatically appear in a new template window if a different template is selected later. Thus, the PCOS template often was not selected.

This project proposed to evaluate selection and use of the PCOS template three months after the educational session. The option for the provider to select the template was not feasible in the clinic setting. The purpose of the template was to create an electronic reminder system for providers with the goal of improving the appropriate diagnosis and management of women with PCOS. To assess whether improvement in diagnosis and management after the educational session occurred, a chart review to assess ordering of appropriate laboratory testing for diagnosis and metabolic screening for development of a management plan was conducted. Currently, whether the provider orders a diagnostic evaluation for women who present with symptoms suggesting PCOS remains dependent on the provider's knowledge.

The second question posed was "Are the appropriate metabolic screens being ordered?" The response was either yes or no. A yes response at either pre or post educational session was selected if the provider ordered a lipid panel, and a fasting glucose or hemoglobin $\mathrm{A} 1 \mathrm{C}$ at either that visit, at the flowing visit, or if those tests had been ordered within the year. Prior to the educational session $64.5 \%$ of the patients had both glucose and lipid levels evaluated and after 
PCOS Project 39

the educational session $82.6 \%$ had this evaluation completed. No statistical difference for frequency of metabolic laboratory testing was found between the pre and post educational session. Lack of a significant difference between screening for a metabolic disease before and after the educational session was expected because 12 cases prior to the educational session had co-morbid conditions that also require glucose and lipid level monitoring.

As a result of this project the primary care providers are more aware of associating the combination of abnormal menstrual patterns and symptoms of excess androgens with the underlying cause of PCOS. Thus a more holistic approach to PCOS management can occur instead of treating the symptoms only. The holistic approach fosters the delay or prevention of the long term health problems that are part of the disease process.

Selection of hirsutism has been added to the general e-template and the provider no longer is required to type this in the chart. By having the selection of "hirsutism", each time a provider charts it acts as a prompt and increases their awareness that abnormal hair patterns in women are an indicator of an endocrine disorder that must be investigated. The results of this project support that education improves provider knowledge. The data does not support that the HealtheWV electronic charting system improves the quality of health care given to PCOS population at this clinic. Further long term studies are required to assess whether health outcomes for women with PCOS improve as a result of electronic charting.

\section{Recommendations}

Technology and the use of electronic patient records is now a necessary part of most health systems. Technology can be a helpful tool for providers that can improve health care delivery. As electronic systems improve with advancing technology, nurses need to be involved with the design. Nurses can bring evidence- based care recommendations for patient care plans 
into charting systems. Nurses can provide knowledge about, not only the disease but also the function of the health care system to technicians who design the systems, so that electronic charting systems become easier to use and are helpful to providers caring for chronically ill patients including women with PCOS. A user friendly system is more likely to be utilized by providers to the fullest capacity for which the technology is designed. Providers will more readily rely on an evidence-based, user friendly tool as an aid to keep them informed and proactive in the care of women with PCOS.

Nurse practitioners and other providers who care for women must be more vigilant about recognizing signs and symptoms of PCOS. Nurse practitioners have the potential to develop national professional meetings and workshops. Such professional educational forums should be encouraged to include content that focuses on PCOS. Nurses who practice at the highest level and implement practice changes based on evidence from research should educate providers through workshops, publications and clinical practice as they care for women who live with PCOS every day. 
PCOS Project 41

\section{References}

Abbott, D.H., Dumesic, D.A. \& Franks, S. (2002), Developmental origin of polycystic ovary syndrome-a hypothesis. Journal of Endocrinology, 174, 1-5.

ACOG Committee on Adolescent Health Care. (2006). The overweight adolescent: prevention, treatment, and obstetric-gynecologic implications. ACOG opinion paper. Obstetrics \& Gynecology, 108(5), 1337-1384.

Adams, S.G., Smith, P.K., Allan. P.F., Anzueto, A., Pugh, J.A., \& Cornell, J.E. (2007). Systematic review of the chronic care model in chronic obstructive pulmonary disease prevention and management. Archives of Internal Medicine, 167(6), 551-561.

Amir, L.H. (2006). Breastfeeding: managing ,supply’ difficulties. Australian Family Physician, 35(9), 686-689.

Azziz, R., Carmina, E., Dewailly, D., Diamanti-Kandarakis, E., Escobar-Morraele, H.F., Futterweit, W., et al. (2006). Position statement: criteria for defining polycystic ovary syndrome as a predominantly hyperandrogenic syndrome: an androgen excess society guideline. The Journal of Endocrinology \& Metabolism, 91(11), 4237-4245.

Azziz, R, Marin, C., Hoq, L., Badamgarav, E., \& Song, P. (2005). Health care-related economic burden of the polycystic ovary syndrome during the reproductive lifespan. Journal of Clinical Endocrinology and Metabolism, 90(8), Retrieved May 2, 2008, from http://www.mdconsult/das/article/body/93749630-2/jorg=juornal\&source=\&sp15704

Balen, A. (2001). Polycystic ovary syndrome and cancer. Human ReproductionUpdate, 7 , $522-5$. 
Betzold, C.M., Hoover, K.L., \& Snyder, C.L. (2004). Delayed lactogenesis II: a comparison of four cases. Journal of Midwifery and Women's Health, 49, 132137.

Birnbaum, M.D. (2003). Poly-cystic ovary syndrome-"PCOS”. Infertility Physician. Retrieved September 4, 2003 from http://www.infertilityphysician.com/androgen/pcos.html

Bodenheimer, T. (2005). Helping patients improve their health-related behaviors: what system changes do we need? Disease Management, 8, 319-330.

Bodenheimer, T., Wagner, E.H., \& Grumbach, K. (2002a). Improving primary care for patients with chronic illness[Electronic version]. The Journal of the American Medical Association, 288(15), 1909-1904.

Bodenheimer, T., Wagner, E.H., \& Grumbach, K. (2002b). Improving primary care for patients with chronic illness: the chronic care model, Part 2. [Electronic version]. The Journal of the American Medical Association, 288(15), 1909-1904.

Corbould, A., Zhao, H., Mirzoeva, S., Aird, F. \& Dunaif, A. (2006). Enhanced mitogenic Signaling in skeletal muscle of women with polycystic ovary syndrome. Diabetes, $55,751-759$.

Cronin, L., Guyatt, G., \& Griffith, L. (1998). Development of a health-related quality of-life questionnaire (PCOSQ) for women with polycystic ovary syndrome (PCOS). Journal or Clinical Endocrinology Metabolism, 83, 1976-1987.

Davis, D.A., Thomson, M.A., Oxman, A.D., \& Haynes, R.B. (1995). Changing physician performance. A systematic review of the effect of continuing medical education strategies. The Journal of the American Medical Association, 274(9), 700-705. 
PCOS Project 43

Diamanti-Kandarakis, E. (2008). Polycystic ovarian syndrome: pathophysiology, molecular aspects and clinical implications. Expert Reviews in Molecular Medicine, $10(\mathrm{e} 3), 1-21$

Diamanti-Kandarakis, E., Papailiou, J., \& Palimeri, S. (2006). Hyperandrogenemia: pathophysiology and its role in ovulatory dysfunction in PCOS. Pediatric Endocrinology Reviews, 3(1), 198-204

Diamanti-Kandarakis, E., \& Piperi, C. (2005). Genetics of polycystic ovary syndrome: searching for the way out of the labyrinth. Human Reproduction Update, 11,(6), 631-643.

Dunaif, A., Givens, J. R., Haseltine, F. P., \& Merriam, G. R. (1992). The polycystic ovary syndrome. Cambridge: Blackwell Scientific Publications.

Elghblawi, E. (2007). Polycystic ovary syndrome and female reproduction. British Journal of Nursing, 16(18), 1118-1121.

Ehrmann, D. A. (2005). Medical progress: polycystic ovarian syndrome. New England Journal of Medicine 352, 1223-1236.

Feifer, C., Ornstein, S.M., Nietert, P.J., \& Jenkins, R.G. (2001). System supports for chronic illness care and their relationship to clinical outcomes. Top Health Information Management, 22(2), 65-72.

Fogel, R.B., Malhotra, A., Pillar, G., Pittman, S.D., Dunaif, A., \& White, D.P. (2001). Increased prevalence of obstructive sleep apnea syndrome in obese women with polycystic ovary syndrome. Journal of Clinical Endocrinology \& Metabolism, 86, 11751180. 
Gandhi, T.K., Kachalia, A., Thomas, E.J., Puopolo, A.L., Yoon, C., Brennan, T.A., et al. (2006). Missed and delayed diagnoses in the ambulatory setting: a study of closed malpractice claims. Annals of Internal Medicine, 145, 488-496

Guardini, I., Talamini, R., Fiorilla, F., Lirutti, M., \& Palese, A. (2008). The effectiveness of continuing education in postoperative pain management: results from a follow-up study. Journal of Continuing Education in Nursing, 39(6), 281-288.

Guzick, D. S. (2004). Polycystic ovary syndrome. Obstetrics and Gynecology, 103(1), 181-193.

Hardiman, P., Pillay, O.C., \& Atiomo, W. (2003). Polycystic ovary syndrome and endometrial carcinoma. Lancet, 361, 1810-1812.

Hart, R., Hickey, M., \& Franks, S. (2004). Definitions, prevalence and syndromes of polycystic ovaries and polycystic ovary syndrome. Clinical Obstetrics \& Gynecology, $18(5), 671-683$.

Healthcare Cost and Utilization Project (HCUP). (2000-2001). Agency for Healthcare Research and Quality, Rockville, MD. Retrieved March 19, 2008, from http://www.hcupus.ahrq.gov/nisoverview.jsp

Hill, K.M. (2003). Update: the pathogenesis and treatment of pcos. The Nurse Practitioner, $23(7), 8-17$.

King, J. (2007). Polycystic ovary syndrome. Journal of Midwifery \& Women's Health, $51(6), 415-422$

Kitzinger, C. \& Wilmot, J. (2002). The thief of womanhood: women's experience of polycystic ovarian syndrome. Social Science Medicine, 541(3), 49-61. 
Kovacs, P. (2006). Viewpoint: lifestyle modification is first-line treatment for PCOS.

Medscape Ob/Gyn \& Women's Health, 11(1). Retrieved February 16, 2006 from http://www.medscape.com/viewarticle/522390

Legro, R.S. (2007). Metformin for infertility in PCOS: going, going, gone. Contemporary Ob/GYN, 54-61. Retrieved April 10, 2008 from http://www.contemporaryobgyn.net

Marasco, L., Marmet, C., \& Shell, E. (2000). Polycystic ovary syndrome: a connection to insufficient milk supply? Journal of Human Lactation, 16(2), 143-148.

Marrinan, G., \& Stein, M. (2007). Polycystic ovary disease (Stein-Leventhal Syndrome). Emedicine. Retrieved March 26, 2008 from http://www.emedicine.com/radio/topic565.htm.

Marx, T.A., \& Mehta, A.E. (2003). Polycystic ovary syndrome: pathogenesis and treatment over the short and long term. Cleveland Clinic Journal of Medicine, 70(1), 3145.

McCulloch, D.K., Price, M.J., Hindmarsh, M., \& Wagner, E.H. (1998). A population-based approach to diabetes management in a primary care setting: early results and lessons learned. Effective Clinical Practice, 1(1), 12-22.

Meisler, J. (2002). Toward optimal health: the experts discuss polycystic ovary syndrome. Journal of Women's Health and Gender-Based Medicine, 11(7), 579-584.

Partnership for Solutions: Johns Hopkins University for the Robert Wood Johnson Foundation. (September 2004 Update). Chronic conditions: making the case for ongoing care. Retrieved June 6, 2008 from http://www.improvingchroniccare.org 
Patton, C.M., (2005). Rural Appalachian women: A vulnerable population in M.C. Chesney (ed.) Caring for the vulnerable: Perspectives in nursing theory, practice, and research, (pp. 277- 282). Boston: Jones and Bartlett.

RAND Corporation. (1999). Improving Chronic illness Care Evaluation. Retrieved July 10, 2008 from http:// www.rand.org/health/projects/icice

Richardson, M.R. (2003). Current perspectives in polycystic ovary syndrome. American Family Physician, 68(4), 697-704.

The Rotterdam ESHRE/ASRM-Sponsored PCOS consensus workshop group. (2004).

Revised 2003 consensus on diagnostic criteria and long-term health risks related to polycystic ovary syndrome (PCOS). Human Reproduction, 19, 41-47.

Salmi, D.J., Zisser, H.C., \& Jovanovic, L. (2004). Screening for and treatment of polycystic ovary syndrome in teenagers. Experimental Biology and Medicine, 229, 369377.

Sheehan, M. (2004). Polycystic ovarian syndrome: diagnosis and management. Clinical Medicine \& Research, 2(1), 13-27.

Siassakos, D., \& Wardle, P. (2007). Polycystic ovary syndrome and pregnancy outcome: red herring or red flag? BJOG An International Journal of Obstetrics and Gynecology, 114, 922-932.

Singh, H., Thomas, E.J., Myrna, M.M., \& Peterson, L.A. (2007). Identifying diagnostic errors in primary care using and electronic screening algorithm. Archives of Internal Medicine, 167(3), 302-308.

Sherif, K. (2006). Polycystic ovary syndrome in primary care. The Female Patient, 31(1), 25-29. 
Snyder, B. S. (2006). The lived experience of women diagnosed with polycystic ovary syndrome. Journal of Obstetric, Gynecology and Neonatal Nursing, 35(3), 384-392.

Stroebel, R., Gloor, B., Freytag, S. Riegert-Johnson, D., Smith, S.A., Huschka, T. (2005). Adapting the chronic care model to treat chronic illness at a free medical clinic. Journal of Health Care for the Poor and Underserved, 16.2, 286-296.

Taylor, A.E. (1998). Understanding the underlying metabolic abnormalities of polycystic ovary syndrome and their implications. American Journal of Obstetrics and Gynecology, 179(6): S94-S100.

Tomlinson, J., \& Pinkney, J. (2007). Diabetes and polycystic ovary syndrome. Practice Nurse, 34(10), 43-7.

Trent, M.E., Rich, M., \& Austin, S.B. (2002). Quality of life in adolescent girls with polycystic ovary syndrome. Archives of Pediatric Adolescent Medicine, 156, 556-560.

Tsilchorozidou, T., Overton, C. \& Conway, G.S. (2004). The pathophysiology of polycystic ovary syndrome. Clinical Endocrinology, 60(1), 1-17.

Urbanek, M., Wu, X., Vicekery, K.R., Kao, L.C., Christenson, L.K., Schneyer, A. et al. (2006). Allelic variants of the follistatin gene in polycystic ovary syndrome. Journal of Clinical Endocrinology and Metabolism, 85, 445-4461.

U.S. Census. (2006a). State and County Quick Facts. Retrieved February 21, 2008 from http://quickfacts.census.gov.qfd/index.html

U.S. Preventive Services Task Force. (2009). The guide to clinical preventive services. Washington, DC:AHRQ Publications Clearinghouse. 
PCOS Project 48

Von Korff, M., Gruman, J., Schaefer, J.K., Curry, S.J., \& Wagner, E.H. (1997).

Collaborative management of chronic illness. Annals of Internal Medicine, 127, 10971102.

Wagner, E.H. (1995). Population-based management of diabetes care. Patient Education and Counseling, 16, 225-230.

Wagner, E.H. (1998). Chronic disease management: what will it take to improve care for chronic illness? Effective Clinical Practice, 1, 2-4.

Wagner, E.H., Austin, B.T., \& Von Korff, M. (1996a). Improving outcomes in chronic illness. Managed Care Quarterly, 4(2), 12-25.

Wagner, E.H., Austin, B.T., \& Von Korff, M. (1996b). Organizing care for patients with chronic illness. Milbank Quarterly, 74, 511-544.

Wild, R.A., Vesely, S., Beebe, L., Whitsett, T. \& Owen, W. (2005). Ferriman Gallwey selfscoring I: performance assessment in women with polycystic ovary syndrome. Journal of Clinical Endocrinology \& Metabolism, 90(7), 4112-4114.

Zoffman, V., Harder, I., \& Kirkevold, M. (2008). A person centered communication and reflection model: sharing decision -making in chronic care. Quality Health Research, 18(5), 670-685. 
PCOS Project 49

Appendix A

Timeline 
PCOS Project 50

Timeline

\begin{tabular}{|c|c|}
\hline Objective & Time Line \\
\hline $\begin{array}{l}\text { Synthesize and organize the current science } \\
\text { Write learning objectives for the education session } \\
\text { Write the content of the education session } \\
\text { Write the pre and post-test } \\
\text { Implement the education session }\end{array}$ & $\begin{array}{l}\text { August 10, } 2008 \\
\text { August } 10,2008 \\
\text { August 10, } 2008 \\
\text { August 10, } 2008 \\
\text { September, } 2008\end{array}$ \\
\hline $\begin{array}{l}\text { Step } 2 \\
\text { Work with the technicians at HealtheWV to develop the } \\
\text { management plan template } \\
\text { Chart Review to determine percentage of PCOS plans } \\
\text { that are initiated at time of diagnosis in the electronic } \\
\text { system occurs }\end{array}$ & $\begin{array}{l}\text { December 15, } 2008 \\
\text { August 15, } 2009\end{array}$ \\
\hline $\begin{array}{l}\text { Step } 3 \\
\text { Analyze the impact of the project by: } \\
\text { 1) Measuring the difference in the mean test scores on the } \\
\text { pre and post test given to providers who attend the session. } \\
\text { 2) Determining the percentage providers initiating the } \\
\text { electronic PCOS care plans initiated by the provider }\end{array}$ & December15, 2009 \\
\hline
\end{tabular}


PCOS Project 51

Appendix B

Budget 


\section{PCOS Capstone Project}

\begin{tabular}{|c|c|c|}
\hline \multirow{2}{*}{\multicolumn{3}{|c|}{$\begin{array}{ll} & \text { Proposed Budget } \\
\text { Personnel }\end{array}$}} \\
\hline & & \\
\hline My time & $\$$ & 0 \\
\hline Secretary support & $\$$ & 0 \\
\hline IT technician time (HealtheWV) & $\$$ & 0 \\
\hline \multicolumn{3}{|l|}{ Supplies } \\
\hline Paper $\$ 10.39 /$ ream & $\$$ & 10.39 \\
\hline Ink $\quad \$ 30.00 /$ per cartridge & $\$$ & 60.00 \\
\hline \multicolumn{3}{|l|}{ Overhead Expense } \\
\hline Telephone expense & Don & y SON \\
\hline Office space & Don & y SON \\
\hline Library Fee if Ind. Project & & paid \\
\hline
\end{tabular}

Source of the cost of supplies is based on Office Depot web site and costs in 2008. 
PCOS Project 53

Appendix C

Pretest-Posttest 
Pre-Test for PCOS Provider Education Session

1. What are the three diagnostic criteria for PCOS based on the 1991 NIH Conference and the Androgen Excess Society in 2006?

A. Polycystic ovaries, insulin resistance, clinical or lab findings of Hyperandrogenism

B. Chronic anovulation, clinical or lab findings of hyperandrogenism, exclusion of other causes of hyperandrogenism

C. Clinical or lab findings of hyperandrogenism, elevated LH:FSH ratio, polycystic ovaries

D. Clinical or lab findings of hyperandrogenism, elevated LH:FSH ratio, insulin resistance

2. All of the following are other causes of hyperandrogenemia EXCEPT:
A. Cushing's Syndrome
B. Non-classical congenital hyperplasia
C. Abnormal LH:FSH ratio
D. Acromegaly

3. Which of the following groups are the recommended diagnostic laboratory studies to order?
A. Total testosterone, 17-hydroxyprogesterone, Prolactin level, TSH
B. Total testosterone, 17-hydroxyprogesterone, LH, FSH
C. Total testosterone, LH, FSH, Insulin level
E. Total testosterone, Pelvic U/S of the ovaries, Fasting blood sugar, Insulin level

4. Women with PCOS are at risk of developing the all of following EXCEPT:
A. Sleep Apnea
B. Ovarian cancer
C. Metabolic syndrome
D. Hyperthyroidism 
PCOS Project 55

5. The management plan for women with PCOS should begin with:
A. Lab screenings for insulin resistance and begin metformin if indicated
B. Life-style changes
C. Prescribe oral contraceptive to protect the uterine lining
D. A pelvic ultrasound to look for cystic ovaries and endometrial stripe size 
PCOS Project 56

Post Test for PCOS Provider Education Session

1. What are the three diagnostic criteria for PCOS based on the 1991 NIH Conference and the Androgen Excess Society in 2006?

A. Polycystic ovaries, insulin resistance, clinical or lab findings of

a. Hyperandrogenism

B. Chronic anovulation, clinical or lab findings of hyperandrogenism, exclusion of other causes of hyperandrogenism

C. Clinical or lab findings of hyperandrogenism, elevated LH:FSH ratio, polycystic ovaries

D. Clinical or lab findings of hyperandrogenism, elevated LH:FSH ratio, insulin resistance

2. All of the following are other causes of hyperandrogenemia EXCEPT:
A. Cushing's Syndrome
B. Non-classical congenital hyperplasia
C. Abnormal LH:FSH ratio
D. Acromegaly

3. Which of the following groups are the recommended diagnostic laboratory studies to order?
A. Total testosterone, 17-hydroxyprogesterone, Prolactin level, TSH
B. Total testosterone, 17-hydroxyprogesterone, LH, FSH
C. Total testosterone, LH, FSH, Insulin level
D. Total testosterone, Pelvic U/S of the ovaries, Fasting blood sugar, Insulin level

4. Women with PCOS are at risk of developing the all of following EXCEPT:
A. Sleep Apnea
B. Ovarian cancer
C. Metabolic syndrome
D. Hyperthyroidism 
5. The management plan for women with PCOS should begin with:
A. Lab screenings for insulin resistance and begin metformin if indicated
B. Life-style changes
C. Prescribe oral contraceptive to protect the uterine lining
D. A pelvic ultrasound to look for cystic ovaries and endometrial stripe size 
PCOS Project 58

Appendix D

Educational Session PowerPoint Slides 


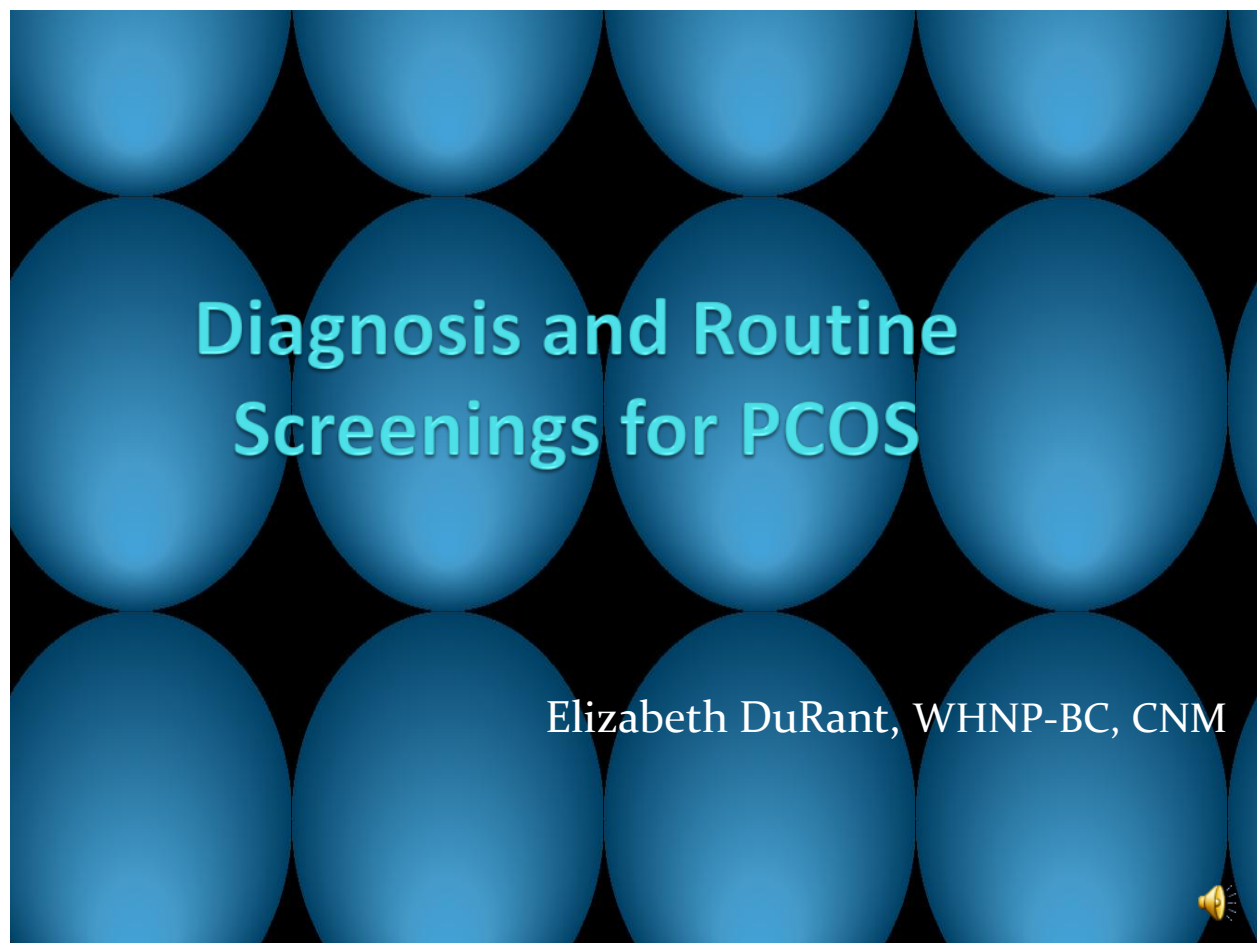

\section{Purpose of Presentation}

- Brief educational unit on PCOS to introduce a management plan that will be found as a chronic illness template in HealtheWV 
At the end of the session the participant:

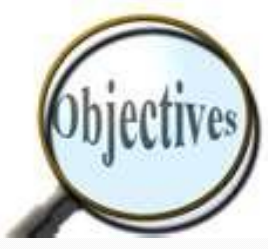

- Will be able to state the diagnostic criteria for PCOS

- Identify other causes of excess androgen that must be excluded

- Identify initial laboratory tests for diagnosis

- Be able to name the risks associated with PCOS

\section{A typical clinical presentation}

- Irregular or absent menstrual cycle

- Episodes of prolong heavy vaginal bleeding $\&$

- Hirsutism and/or Acne

or

- Inability to conceive

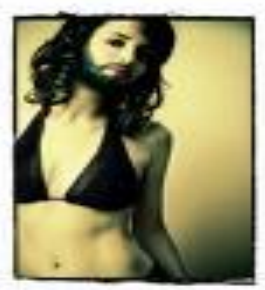




\section{Diagnostic Criteria}

\begin{tabular}{|c|c|c|}
\hline NIH 1991 Conference & $\begin{array}{l}\text { Rotterdam Consensus } \\
2003 \text { (2 of } 3)\end{array}$ & $\begin{array}{l}\text { Androgen Excess Society } \\
\text { (AES) } 2006 \\
\text { Anonocen Excess Sockiy }\end{array}$ \\
\hline Chronic anovulation & Oligo-and/or anovulation & $\begin{array}{l}\text { Oligo or anovulation \&/or } \\
\text { polycystic ovaries }\end{array}$ \\
\hline $\begin{array}{l}\text { Clinical signs or androgen } \\
\text { excess \&/or } \\
\text { Elevated Testosterone } \\
\text { Levels }\end{array}$ & $\begin{array}{l}\text { Clinical signs \&/or } \\
\text { Elevated testosterone } \\
\text { Levels }\end{array}$ & $\begin{array}{l}\text { Clinical signs of androgen } \\
\text { excess \&/or } \\
\text { Elevated Testosterone Levels }\end{array}$ \\
\hline Exclusion of other causes & Polycystic ovaries* & Exclusion of other causes \\
\hline \multicolumn{3}{|c|}{$\begin{array}{l}\text { Rotterdam Consensus } 2003 \text { also includes exclusion of other causes as part of the diagnostic criteria. } \\
\text { * Polycystic ovaries are defined as having at least } 12 \text { or more follicles measuring between two to } \\
\text { nine millimeters in diameter or an enlarged ovarian volume of greater than } 10 \text { millimeters cubed } \\
\text { (Balen, Laven, Tan, 2003). }\end{array}$} \\
\hline
\end{tabular}

\section{Which one to follow?}

- ACOG follows the NIH \& AES definitions. (ACOG, 2007).

Anorocen Excess Soceiv

- The Women's Health Certificate Program, and Internal Medicine use the Rotterdam Criteria

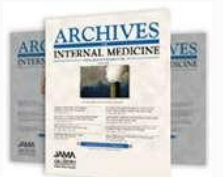




\section{Differential and Similar Clinical Features}

\begin{tabular}{|l|c|l|l|}
\hline Condition & $\begin{array}{l}\text { Signs of excess } \\
\text { androgen }\end{array}$ & $\begin{array}{l}\text { Oligo or } \\
\text { amenorrhea }\end{array}$ & $\begin{array}{l}\text { Clinical Differential } \\
\text { features }\end{array}$ \\
\hline $\begin{array}{l}\text { *Non-classical } \\
\text { Congenital adrenal } \\
\text { hyperplasia }\end{array}$ & Yes & $\begin{array}{l}\text { Usually but } \\
\text { may have } \\
\text { regular cycles }\end{array}$ & $\begin{array}{l}\text { Fam Hx of infertility, } \\
\text { hirsutism or both; } \\
\text { Ashkenazi Jewish } \\
\text { Ancestry }\end{array}$ \\
\hline $\begin{array}{l}\text { Cushing's } \\
\text { Syndrome }\end{array}$ & Yes & Yes & $\begin{array}{l}\text { HTN, striae, easy } \\
\text { bruising, upper body } \\
\text { obesity with thin } \\
\text { extremities, round } \\
\text { face, thick neck }\end{array}$ \\
\hline $\begin{array}{l}\text { Hyper- } \\
\text { prolactinemia }\end{array}$ & None or Mild \\
( DHEAS) & Yes & Galactorrhea \\
\hline $\begin{array}{l}\text { Primary } \\
\text { Hypothyroidism }\end{array}$ & None or Mild & May be present & $\begin{array}{l}\text { Goiter maybe } \\
\text { present }\end{array}$ \\
\hline
\end{tabular}

\section{Differential and Similar Clinical Features}

\begin{tabular}{|c|c|c|c|}
\hline Condition & $\begin{array}{l}\text { Signs of excess } \\
\text { androgen }\end{array}$ & $\begin{array}{l}\text { Oligo or } \\
\text { amenorrhea }\end{array}$ & $\begin{array}{l}\text { Clinical Differential } \\
\text { features }\end{array}$ \\
\hline Acromegaly & None or Mild & Usually & $\begin{array}{l}\text { Enlarged arms, } \\
\text { hands, fingers, legs, } \\
\text { ears w/ course } \\
\text { features, } \\
\text { Prognathism }\end{array}$ \\
\hline $\begin{array}{l}\text { Premature ovarian } \\
\text { failure }\end{array}$ & None & Yes & $\begin{array}{l}\text { Associated w/ } \\
\text { autoimmune } \\
\text { endocrinopathies }\end{array}$ \\
\hline Simple Obesity & May be & $\begin{array}{l}\text { Possible, not } \\
\text { often }\end{array}$ & $\begin{array}{l}\text { Dx of exclusion of } \\
\text { other causes }\end{array}$ \\
\hline $\begin{array}{l}\text { Virilizing adrenal } \\
\text { or ovarian } \\
\text { neoplasm }\end{array}$ & Yes & Yes & $\begin{array}{l}\text { Clitoromegaly, } \\
\text { extreme hirsutism or } \\
\text { male-pattern } \\
\text { alopecia }\end{array}$ \\
\hline Drug-related & Often & Possible & Evidence by $\mathrm{Hx}$ \\
\hline
\end{tabular}




\section{What to order for Dx}

- Total testosterone

-17-hydroxyprogesterone (17-OHP)

- Prolactin level

- Thyroid Stimulating Hormone (TSH)

\section{Other potential Dx Labs}

- DHEAS if testosterone is extremely elevated suggesting an androgen secreting adrenal tumor.

- If $17-\mathrm{OHP}$ is $>200 \mathrm{ng} / \mathrm{dl}$ then refer for an ACTH level. When $17-\mathrm{OHP}>$ than $800 \mathrm{ng} / \mathrm{dl}$ then a diagnosis of $\mathrm{CAH}$ may be made. 
Secondary Causes of Hyperandrogenism \& Diagnostic Lab Findings

\begin{tabular}{|l|l|l|}
\hline Disease & Lab findings & Dx values \\
\hline -Pituitary Tumor & -Elevated prolactin & $>150 \mathrm{ng} / \mathrm{ml}$ \\
-Adrenal tumors & 'Elevated DHEA/DHEAS & $>700 \mathrm{ng} / \mathrm{dl}$ \\
-Ovarian tumors & -Elevated testosterone & $>150 \mathrm{ng} / \mathrm{dl}$ \\
-Non-classic CAH & -Elevated 17-OH progesterone & $>800 \mathrm{ng} / \mathrm{dl}$ \\
-Hypercortisolism & $\begin{array}{l}24 \mathrm{hr} \text { urine collection level of } \\
\text { cortisol }\end{array}$ & $24 \mathrm{hr} \mathrm{mcg} /$ \\
& & \\
\hline
\end{tabular}

Buccola \& Reynolds. (2003). Polycystic Ovarian Syndrome: a review for primary providers. Primary Care: Clinics in Office Practice $30(4)$

\section{Optional testing to consider}

- Ultrasound evaluation of the pelvis for baseline evaluation and assessment of sudden onset of excess androgen symptoms.

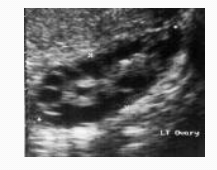

- Gonadotrophin levels if evaluating causes of amenorrhea. 


\section{Health Risks Associated w/ PCOS}

- Metabolic disorders

1. Central obesity - waist to hip ratio $>0.72$

2. HTN

3. Dyslipidemia

4. Nonalcoholic fatty liver

5. Coronary calcifications

6. Abnormal C-reactive protein

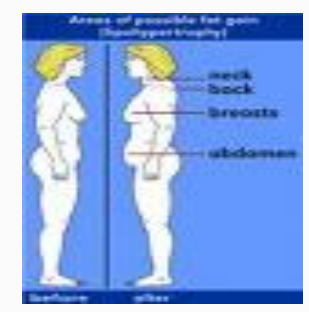

\section{Health Risks Associated w/ PCOS}

- Reproductive System Cancers

1. Endometrial hyperplasia

2. Endometrial cancer

3. Ovarian cancer

4. Breast cancer

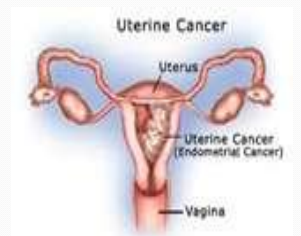

- Most likely due to years of unopposed estrogen 


\section{Health Risks Associated w/ PCOS}

- Sleep Apnea

Despite BMI women with PCOS have a 30 fold increase in the incidence of sleep apnea

- Depression

- Infertility

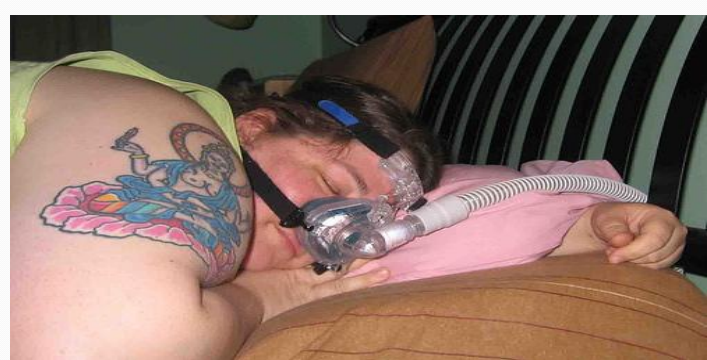

\section{Labs to monitor health status}

- 2 hr Oral Glucose Tolerance Test Fasting B/S often miss IR PCOS $q$ Optimal screening interval is not known < every 3 years in high risk persons.

- Lipid panel - Optimal interval for screening is uncertain. Decisions should take into account overall risk of heart disease 


\section{Screenings to Detect Cancer}

- Endometrial Cancer

No effective screening method

Endometrial Bx for abnormal bleeding

TV/US or trans-abdominal

US cannot Dx but can provide information to aid in Dx

\section{Screenings to Detect Cancer}

- Ovarian Cancer

No effective screening method

Maintain a high degree of suspicion and monitor

for Sx (bloating, early satiety, sudden abd. girth increase)

- Breast Cancer

Annual CBE

Mammography* every $1-2$ yrs beginning at age 40 or with abnormal CBE findings

*BCCSP - Age 50 


\section{Management of PCOS}

- Early recognition can delay or prevent complications

- Depends on the presenting signs and symptoms

- Lifestyle modification is $1^{\text {st }}$ line treatment

\section{Management of PCOS \\ - Hirsutism \& Acne - COCP, \\ Spironolactone, Mechanical hair removal}

- Treat the unopposed estrogen state with an OCP or DMPA. Yaz ${ }^{\circledR}$ is the OCP of first choice. If not available select a pill $\mathrm{w} /$ low or nonandrogenic progesterone effects. 


\section{Management of PCOS}

- Abnormal Menstrual Pattern -

1. Cyclic progesterone or COCP

2. Without hormone therapy - regular ultrasound to monitor endometrial thickness

\section{Management of PCOS}

- Screen for signs of metabolic syndrome - Metformin?

- Screen for and order a sleep study if symptoms indicate a need.

- Screen for depression at each visit 


\section{Follow Up}

- Depends on individual signs, symptoms, \& treatment plan

- Every 6 months for abnormal B/P, fasting glucose, and lipids

- Every 3-6 months initially for anti-androgen therapy

- Yearly CBE, pelvic exam and mammogram if indicated.

\section{HEALTHeWV}

- Following the other HeatheWV electronic chronic care models, a model for the management is being developed and will be available.

- ? Questions? 


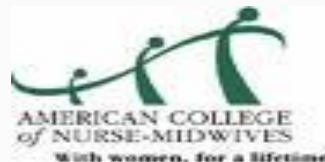

With Women for a Lifetime

\section{Thank YOU}

For listening 
Appendix E

Table 1 Test Scores from Educational Session 
PCOS Project 73

Table 1 Test Scores from Educational Session

\begin{tabular}{lll}
\hline & Pretest & Post test \\
\hline $\mathrm{N}$ & 10 & 8 \\
Mean & 1.50 & 4.25 \\
Minimum & 0 & 3 \\
Maximum & 3 & 5
\end{tabular}


Appendix F

Table 2 Educational Session Test Statistics 
PCOS Project 75

Table 2 Educational Session Test Statistics

\begin{tabular}{lr}
\hline Mann-Whitney U & .500 \\
Wilcoxon W & 55.500 \\
Z & -3.579 \\
Asymp.Sig. (2-tailed) & .000 \\
Exact Sig, \{2* (1-tailed Sig,)] & .000
\end{tabular}


PCOS Project 76

Appendix G

Figure 1 Questions Answered Correctly 
Figure 1 Questions answered correctly

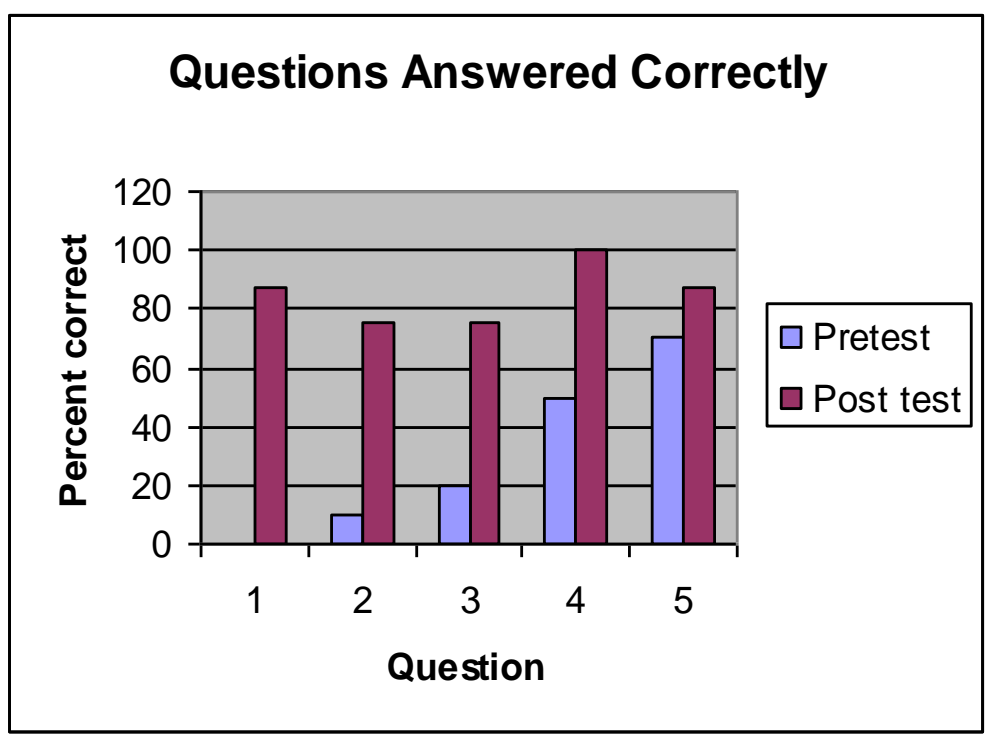


PCOS Project 78

Appendix $\mathrm{H}$

PCOS Template 


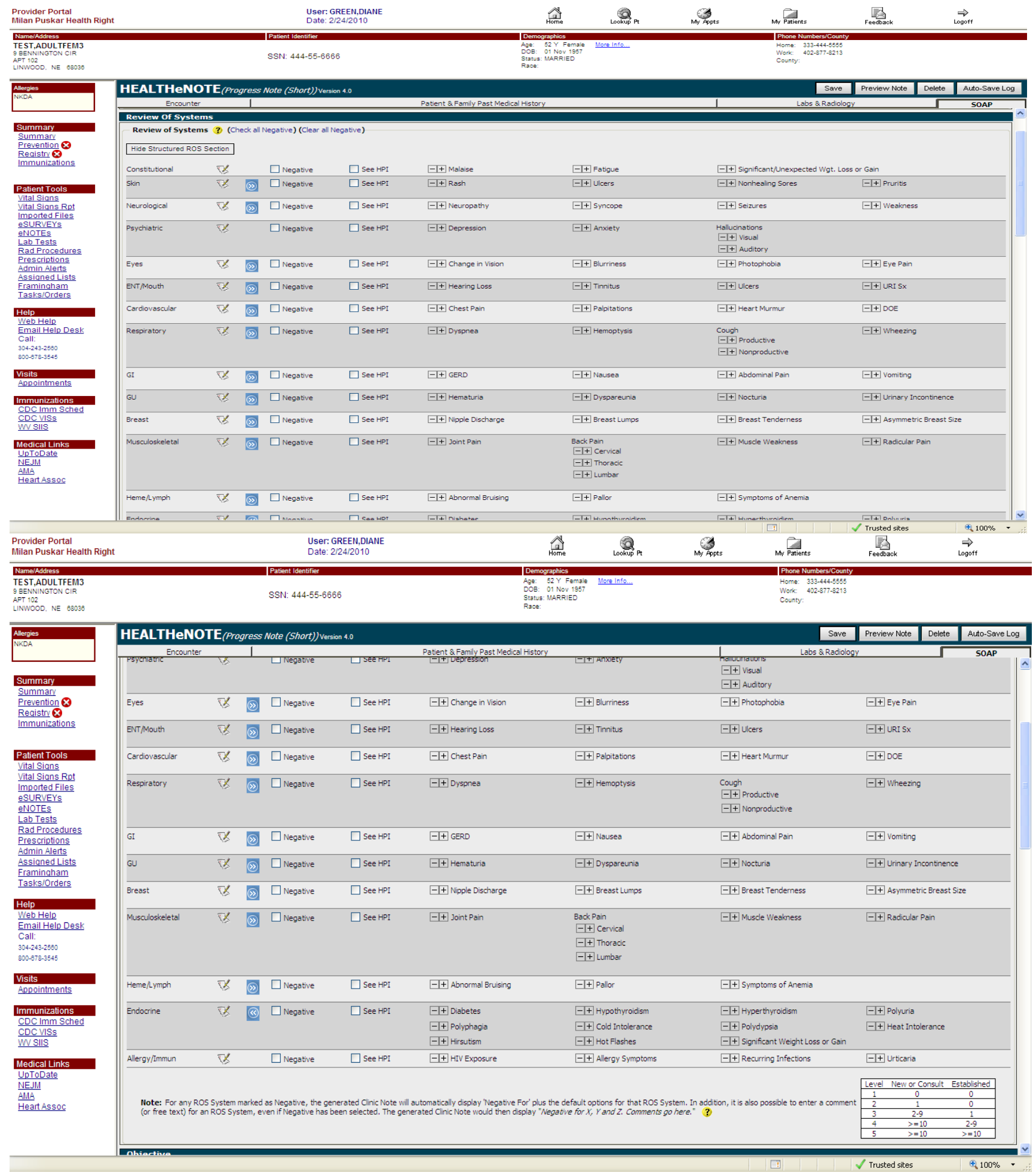


Appendix I

Table 3 Appropriate Diagnostic Testing 
PCOS Project 81

Table 3 Appropriate Diagnostic Testing

\begin{tabular}{lll}
\hline & $\mathrm{N}$ & Percent \\
\hline $\begin{array}{l}\text { Pre Education Cases with } \\
\text { Appropriate Diagnostic Labs }\end{array}$ & 10 of 31 & 32.3 \\
& & \\
& & \\
Post Education Cases with & 16 of 23 & 69.6 \\
Appropriate Diagnostic Labs & &
\end{tabular}


PCOS Project 82

\section{Appendix J}

Figure 2 Percentage of Appropriate Diagnostic Laboratory Tests Ordered 
Figure 2 Percentage of Appropriate Diagnostic Laboratory Tests Ordered

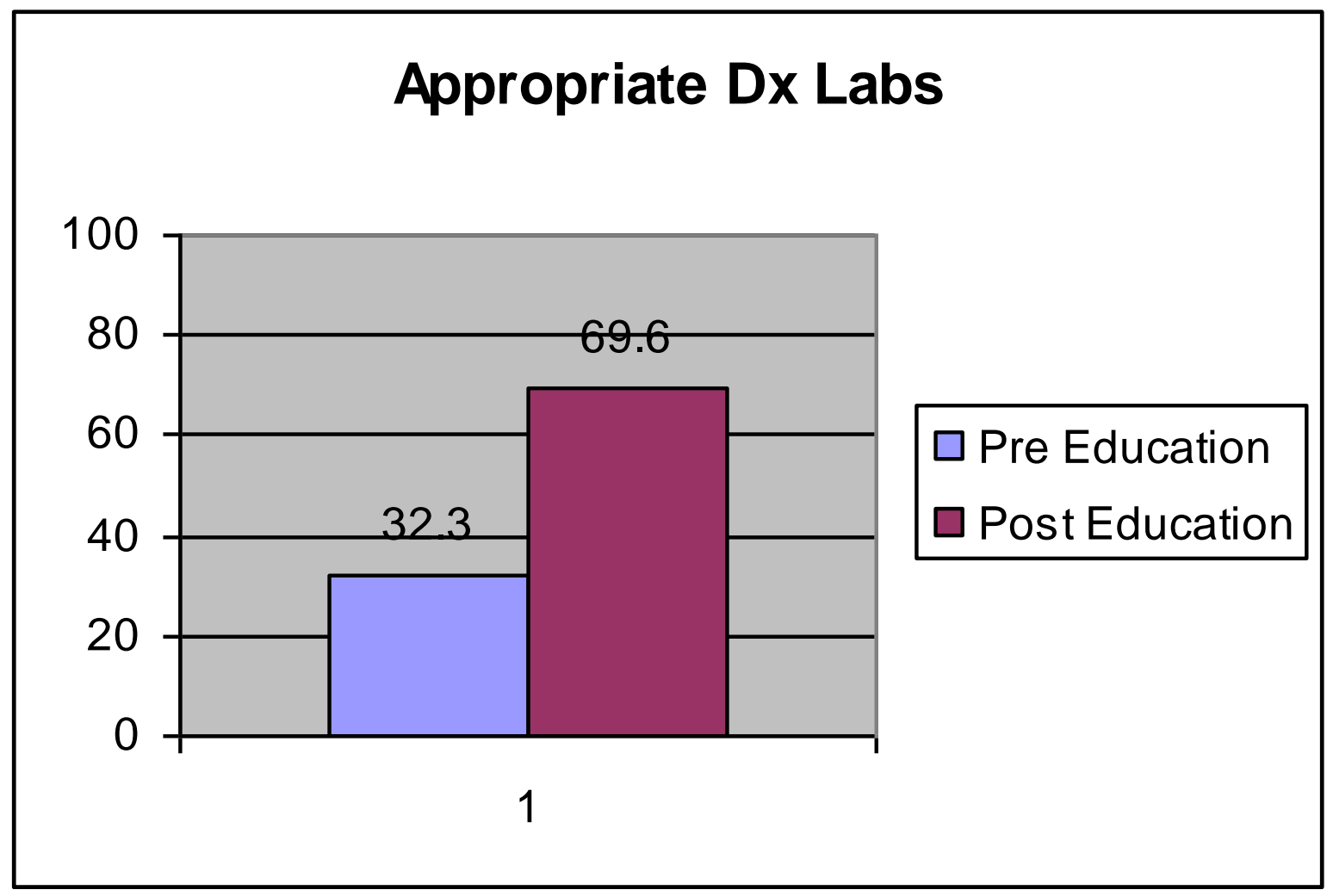


Appendix K

Table 4 Appropriate Metabolic Screening Tests 
PCOS Project 85

Table 4 Appropriate Metabolic Screening Tests

\begin{tabular}{lcc}
\hline & N & Percent \\
\hline $\begin{array}{l}\text { Pre Education Cases with } \\
\text { Appropriate Metabolic Screenings }\end{array}$ & 20 of 31 & 64.5 \\
$\begin{array}{l}\text { Post Education Cases with } \\
\text { Appropriate Metabolic Screenings }\end{array}$ & 19 of 23 & 82.6
\end{tabular}


Appendix L

Figure 3 Appropriate Metabolic Screening Tests 
Figure 3 Appropriate Metabolic Screening Tests

\section{Metabolic Screening Tests}

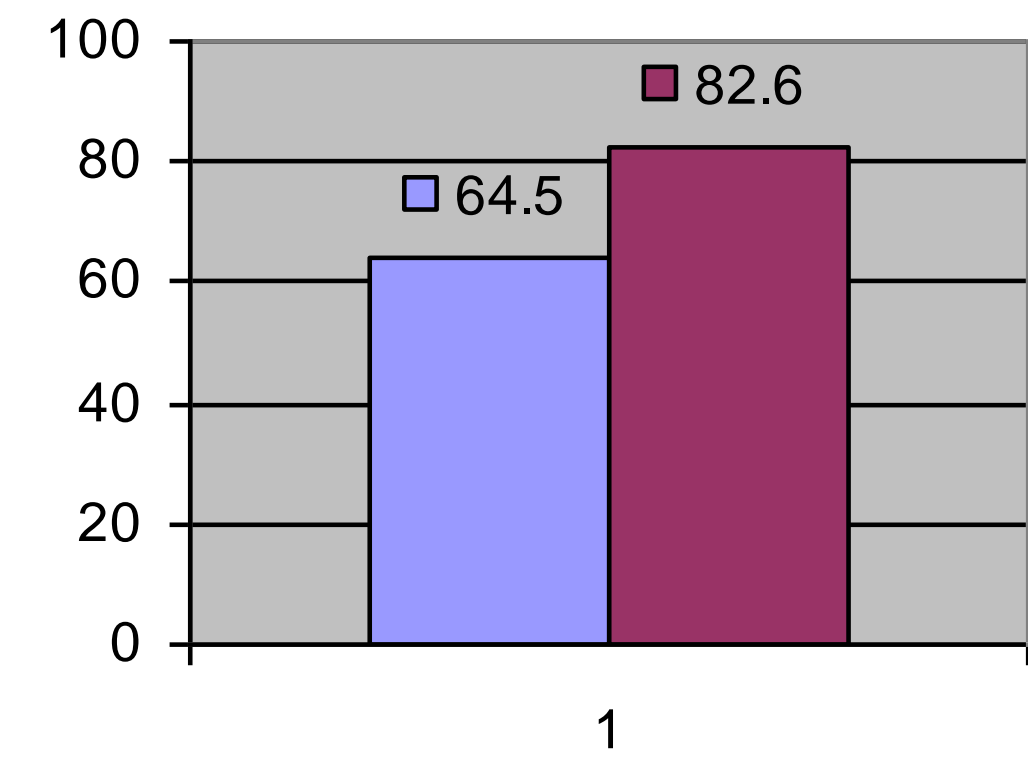

$\square$ Pre Education

$\square$ Post Education

John $\mathrm{H}$. 